\title{
LA TECNOLOGÍA CERÁMICA EN LA CUENCA DEL ARROYO CHASICÓ. UNA APROXIMACIÓN A LA MOVILIDAD DE LAS SOCIEDADES DEL HOLOCENO TARDÍO DE PATAGONIA NORORIENTAL Y DE LA REGIÓN PAMPEANA SUDESTE, ARGENTINA
}

LUCIANA CATELLA ${ }^{a}$

\section{RESUMEN}

El objetivo de este trabajo es presentar las características de los materiales cerámicos recuperados en la cuenca del arroyo Chasicó (Provincia de Buenos Aires, Argentina), localizada en la transición entre los ambientes pampeanos y nordpatagónicos y analizar dicha información en relación con aquella generada para diferentes áreas del NE de Patagonia y sur de la Región Pampeana. Se describen las características tecnológicas, morfológicas y estilísticas y se las discute en relación con distintas propuestas teóricas acerca del rol de la cerámica en sociedades cazadoras-recolectoras móviles. Los datos obtenidos en la cuenca del arroyo Chasicó son empleados junto con datos secundarios del NE de Patagonia y sur de la Región Pampeana a los fines de generar modelos estadísticos y espaciales que permitan identificar patrones $\mathrm{y} / \mathrm{o}$ tendencias de escala macroregional. En líneas generales, la cerámica procedente de la cuenca del arroyo Chasicó se caracteriza por una escasa estandarización y baja a moderada inversión de tiempo y energía. Los motivos decorativos muestran reglas de composición compartidas y elementos comunes con aquellos descriptos para el SE de la Región Pampeana y NE de Patagonia, así como con algunos motivos presentes en otros soportes muebles. A escala local, la cerámica presenta frecuencias y características tecnológicas que permiten proponer su uso en actividades relacionadas con la cocción de sustancias, en un contexto de alta movilidad residencial. A escala regional, los resultados evidencian cierta tendencia hacia una mayor frecuencia de materiales cerámicos en aquellas áreas geográficas donde se encuentran disponibles especies arbóreas de la provincia fitogeográfica del Espinal junto a recursos ictícolas.

PALABRAS CLAVE: cazadores-recolectores, tecnología cerámica, movilidad, transición pampeano-patagónica.

\section{CERAMIC TECHNOLOGY IN THE CHASICÓ BASIN. AN APPROACH TO LATE HOLOCENE SOCIETIES` MOBILITY IN NORTHEASTERN PATAGONIA AND THE SOUTHEASTERN PAMPEAN REGION, ARGENTINA}

\begin{abstract}
This paper aims to characterize ceramic materials recovered in the Chasicó basin (Buenos Aires

a CONICET. División Arqueología, Facultad de Ciencias Naturales y Museo, Universidad Nacional de La Plata, paseo del Bosque s/n (1900) La Plata, Buenos Aires, Argentina. CEAR, Facultad de Humanidades y Artes, Universidad Nacional de Rosario. catellaluciana@hotmail.com
\end{abstract}


province, Argentina), located in the transition between Pampean and Patagonian environments, and to analyze this data in relation with data from areas of the southern Pampean Region and the NE of Patagonia. Technological, morphological and stylistic characteristics are described and discussed in regard to different theoretical proposals about the role of pottery in mobile hunting and gathering societies. Data obtained from the Chasicó basin are used with secondary data from the NE of Patagonia and the southern region of the Pampas in order to generate statistical and spatial models that allow the identification of macro-regional patterns and trends. Chasicó basin pottery is characterized by a poor standardization and low to moderate investment of time and energy. Decorative motifs show shared compositional rules and elements common to those described for the SE of the Pampas and NE of Patagonia, as well as to some motifs represented in other mobile items. At the local level, the number of ceramics and their technological characteristics suggest their use in activities related to cooking of substances in a context of high residential mobility. At the regional scale, the results show a higher frequency of ceramic in those geographical areas where tree species from the phytogeographic province of Espinal are available along with fish resources.

KEY WORDS: hunter-gatherers, ceramic technology, mobility, pampean-patagonia transition.

\section{INTRODUCCIÓN}

En el NE de Patagonia y SE de la Región Pampeana, la incorporación de la tecnología cerámica por parte de las sociedades cazadorasrecolectoras, se produjo durante el Holoceno tardío (Eugenio \& Aldazabal, 2013; Politis et al. 2001), en un contexto de cambios que habrían incluido -en algunas áreas al menos- mayor densidad poblacional, reducción en la movilidad residencial, aumento en la producción y costos de procesamiento de los recursos, mayor énfasis en la organización logística y ampliación de las redes sociales y circuitos de intercambio (Berón, 2004; González, 2005; Politis \& Madrid, 2001; Martínez, 2010). Considerando este contexto, se ha propuesto que los contenedores cerámicos habrían permitido almacenar y procesar recursos alimenticios así como crear y expresar relaciones sociales, por medio de información de contenido simbólico, codificada en sus distintos aspectos estilísticos (González, 2005; González et al. 2007; Martínez, 2002; Politis et al. 2001).

Si bien el material cerámico en el NE de Patagonia y SE de la Región Pampeana, es fragmentario y relativamente escaso, su estudio permite abordar diferentes aspectos de la organización de las sociedades del pasado, ya que ciertas características de esta tecnología (e.g. funcionalidad y vida útil de los artefactos, requerimientos asociados con su proceso de manufactura) poseen implicancias en términos de los ambientes, patrones de movilidad y uso de recursos más apropiados para su implementación.

En los últimos años se han incrementado considerablemente, en las regiones de interés, los trabajos orientados a caracterizar funcional, tecnológica y estilísticamente a los materiales cerámicos de origen arqueológico. En efecto, a partir de la aplicación de diversas técnicas analíticas, se ha generado abundante información acerca de los modos de manufactura, características petrográficas de la pasta, motivos decorativos representados -sus recurrencias y posibles modos de generación-, recursos procesados y morfologías representadas (Aldazabal, 2008; Borges Vaz et al. 2016; Cassiodoro \& Tessone, 2014; Catella, 2014; Di Prado, 2013, 2015, 2016; Frère, 2015; González, 2005; González et al. 2012; Madrid, 1997; Oliva \& Panizza, 2014). Los materiales cerámicos también han aportado información que permite indagar acerca de los posibles modos de interacción e intercambio, de información y bienes establecidos entre grupos de diferentes áreas (Aldazabal, 2008; Aldazabal et al. 2015; Di Prado, 2015; González et al. 2007).

Enestetrabajose presentanlascaracterísticas tecnológicas, morfológicas y estilísticas de los materiales cerámicos recuperados en la cuenca del arroyo Chasicó (Provincia de Buenos Aires, Argentina), localizada en la transición entre los ambientes pampeanos y nordpatagónicos. Esta 
información es puesta en relación con aquella obtenida por otros investigadores en áreas vecinas del NE de Patagonia y sur de la Región Pampeana, mediante la generación de modelos espaciales y estadísticos. De este modo, a través del análisis de la información a diferentes escalas espaciales, se busca identificar tendencias que permitan discutir los posibles modos de producción y uso de los contendores cerámicos, su relación con la distribución de recursos locales y el grado de movilidad residencial de las sociedades cazadorasrecolectoras que habitaron esta zona durante el Holoceno tardío.

\section{ÁREA DE ESTUDIO}

El sector centro-oriental de la República Argentina, localizado entre $36^{\circ}$ y $41^{\circ}$ de lat. Sur y $57^{\circ}$ y $67^{\circ}$ de long. Oeste, comprende el sur de la Región Pampeana y el NE de la Región Patagónica. La Región Pampeana se encuentra dividida por la isohieta de los $600 \mathrm{~mm}$ en Pampa Seca al oeste y Pampa Húmeda al este. Esta última subdividida a su vez, sobre la base de rasgos fisiográficos y, complementariamente, arqueológicos, en siete áreas: Sur, Ventania, Interserrana, Tandilia, Oeste, Depresión del Salado, Norte y Delta, estas dos últimas por fuera del sector centro-oriental considerado en este trabajo (Berón \& Politis, 1997).

La cuenca del arroyo Chasicó se localiza en el sector sur de la denominada Área Ecotonal Húmedo-Seca Pampeana (AEHSP, sensu Oliva, 2006), más precisamente en la zona de transición entre las regiones Pampeana y Patagónica. Esta cuenca surca transversalmente lo que puede ser considerado un ecotono pampeano-patagónico, vinculando el Sistema Serrano de Ventania, donde predominan los recursos bióticos relacionados con la Pampa Húmeda, con los bajos ocupados por la laguna Chasicó y las Salinas Chicas, al sur de los cuales se desarrollan los paisajes patagónicos de meseta, con zonas bajas de salares o salitrales y recursos propios de las provincias fitogeográficas del Monte y Espinal, entre los que se encuentran abundantes especies arbóreas y arbustivas. Este límite no debe ser visto como algo estático, sino como una zona transicional fluctuante, donde las variaciones climáticas ocurridas durante el Holoceno y, particularmente durante los últimos 4.000 años, habrían generado oscilaciones en la distribución de los organismos en relación con las condiciones ambientales de cada momento (Quattrocchio et al. 2008).

La cuenca del arroyo Chasicó consiste en un sistema endorreico de $120 \mathrm{~km}$ de longitud y desarrollo NE-SO, que abarca una superficie total de $3764 \mathrm{~km}^{2}$. Considerando sus características topográficas e hidrológicas, puede ser subdividida en tres sectores. La subcuenca superior, comprende las nacientes -conformadas por varios arroyos que drenan las sierras de Ventania- hasta la laguna Los Chilenos; la subcuenca media, abarca el sector de llanura desde la laguna Los Chilenos, donde nace el arroyo Chasicó propiamente dicho, hasta la confluencia entre éste y el arroyo Sanquilcó Grande, incluyendo también al arroyo Pelicurá; finalmente la subcuenca inferior, comprende el último tramo del arroyo Chasicó hasta la laguna homónima, donde encuentra su nivel de base a unos menos 20 msnm (Bonorino et al. 1989) (Fig. 1).

\section{LA TECNOLOGÍA CERÁMICA EN CAZADORES-RECOLECTORES}

Características de la cerámica en

sociedades cazadoras-recolectoras

En el caso de sociedades cazadorasrecolectoras, la tecnología cerámica se utiliza, principalmente, para la elaboración de contenedores utilizados para hervir alimentos y para re-hidratar y/o ablandar carne o semillas (Dean \& Heath, 1990; Hill, 2006; Linton, 1944; Reid, 1989). La producción de los contenedores cerámicos involucra una serie de pasos que incluyen la elección de arcillas y antiplásticos, su procesamiento y mezcla, en relación con propiedades particulares vinculadas tanto con la elaboración de la pieza, modelado (incluyendo tratamiento de las superficies y decoración), secado y cocción, como con su posterior funcionalidad (Orton et al. 1997; Rice, 1987). Las elecciones realizadas durante este proceso estarán, a su vez, estrechamente relacionadas con la tecnología y el tiempo disponible durante la producción y uso de los contenedores. En este sentido, su manufactura implica que el 


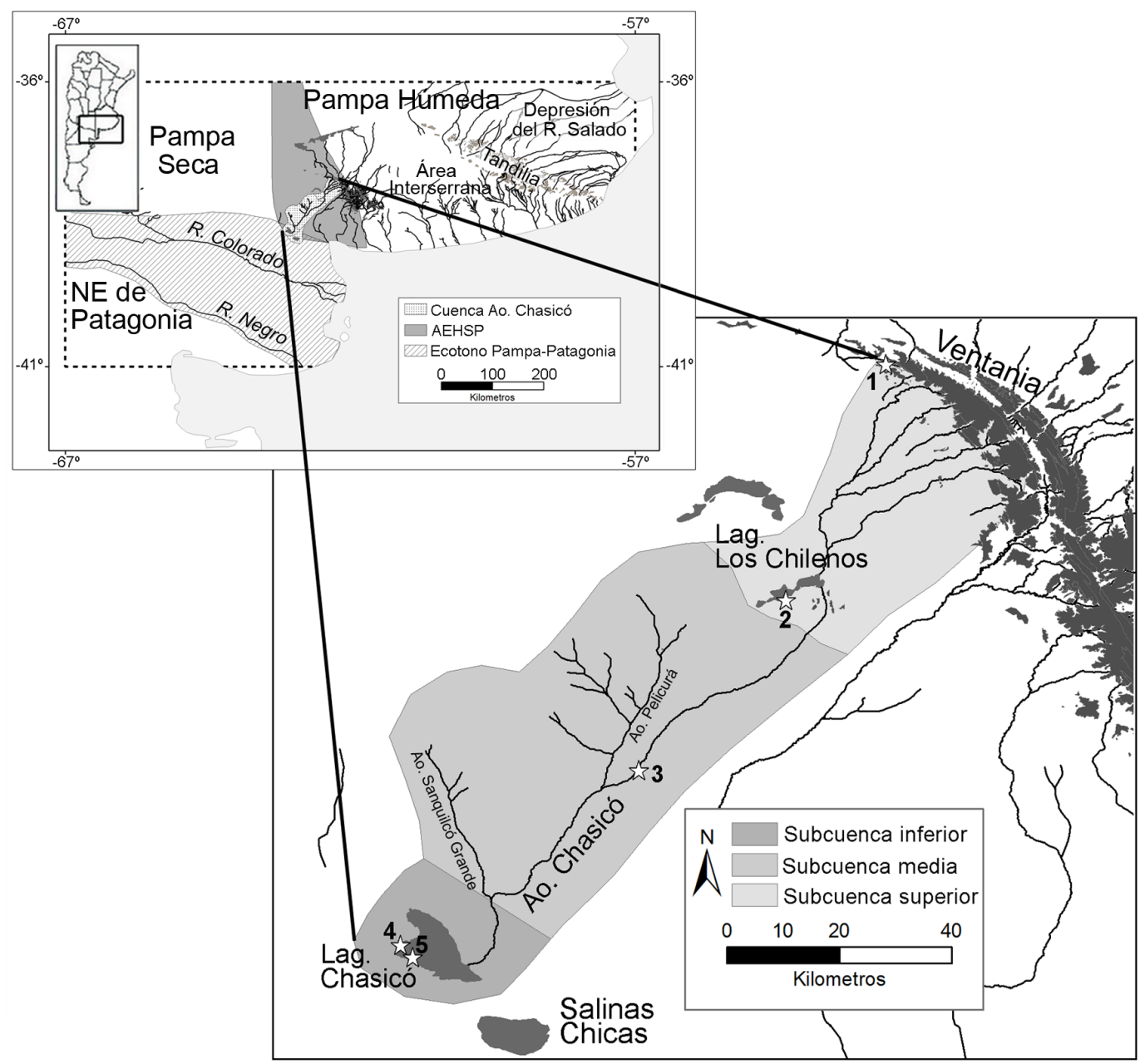

Fig. 1. Área de estudio. Arriba sector centro-oriental de la República Argentina, donde se encuentran comprendidas el sur de la Región Pampeana y el NE de Patagonia. Abajo cuenca del arroyo Chasicó y sitios considerados en este trabajo: 1- La Montaña sitio 1; 2- Laguna los Chilenos sitios 1 y 2; 3- Colección San Martín; 4- Laguna Chasicó sitios 2 y 3; 5- Laguna Chasicó sitio 1.

ceramista permanezca en un mismo lugar por al menos dos a cuatro días en la estación seca (sin considerar el tiempo de obtención y preparación de la arcilla), que pueden ser más en el caso de condiciones ambientales de abundante humedad ${ }^{1}$. Por otra parte, si su elaboración se realiza preferentemente durante el verano, estación seca

1 Además de la obtención y preparación de la arcilla, la manufactura cerámica implica una serie de pasos consistentes en el amasado y modelado, la eventual decoración, el secado y la posterior cocción de la pieza. El tiempo de secado varía en función de la humedad ambiente, la composición de la pasta y el espesor de las paredes (Cremonte, 1983-1985). Actualmente, en la localidad de y/o de mayor radiación solar, también puede competir temporalmente con la recolección de semillas. A su vez, el peso, volumen y fragilidad de este tipo de utensilios puede dificultar su traslado, volviéndolos menos eficaces que otro tipo de contenedores, como los realizados a partir de materiales orgánicos, sobre todo bajo condiciones

Villa Gesell, localizada en la costa atlántica de la provincia de Buenos Aires, $550 \mathrm{~km}$ al NO del área de estudio, la ceramista Gabriela Zavalia, durante el verano (estación en que la evaporación es mayor), demora al menos 24 hrs en el proceso de secado de vasijas con paredes de entre cinco $\mathrm{mm}$ y ocho $\mathrm{mm}$ de espesor. 
que inhiben un reemplazo efectivo de las unidades perdidas, como es el caso de las sociedades con alta movilidad residencial (Arnold, 1985; Simms et al. 1997; Skibo et al. 1989).

Algunos autores han considerado la posibilidad de que las características mencionadas (la fragilidad de las vasijas cerámicas, su peso y el tiempo necesario para su confección), puedan ser limitantes al momento de su incorporación por parte de las sociedades móviles (Arnold, 1985). Otros investigadores, en cambio, sostienen que la movilidad no sería un impedimento para su incorporación, si bien impondrá ciertas restricciones, influyendo en los modos de fabricación y uso de estos instrumentos, así como en su tamaño y peso, que tenderán a disminuir al aumentar la movilidad residencial (Bright \& Ugan, 1999; Eerkens, 2003, 2008; Eerkens et al. 2002; Rice, 1987; Simms et al. 1997; Skibo et al. 1989). Simms et al. (1997) postularon que la inversión de tiempo y energía realizada en la elaboración de contenedores cerámicos, está condicionada por el tiempo de uso de estos y, por lo tanto, se verá afectada por el grado de movilidad residencial, la redundancia ocupacional y la presencia o no de un sistema logístico de uso del espacio. Estos autores proponen que en aquellas sociedades con menor movilidad residencial o bien con alta redundancia ocupacional, donde las vasijas pueden ser guardadas en el sitio para futuras visitas (en la forma de caches), el tiempo de uso de la cerámica aumentará y por lo tanto será esperable una mayor inversión en su fabricación, observable en paredes de espesor fino, una buena selección del tamaño de los antiplásticos -expresado en pastas finas y homogéneas- y superficies mejor terminadas, en tanto en las sociedades más móviles, y con menor redundancia ocupacional, será esperable una menor inversión de tiempo y esfuerzo en la manufactura cerámica (Simms et al. 1997). A su vez, Eerkens (2003) observa cierta relación entre la cantidad de cerámica utilizada y el grado de redundancia ocupacional, postulando que la utilización de recursos alimenticios espacialmente predecibles puede ser un factor de importancia en la cantidad de vasijas cerámicas fabricadas, dado que esta situación permite que los contenedores puedan ser almacenados en ciertos lugares puntuales del paisaje para su futuro uso. Por otra parte, este autor expresa que en aquellas sociedades con mayor movilidad residencial, las vasijas tenderán a ser morfológicamente menos variables, con bocas más angostas, paredes un poco más finas, superficies externas rugosas y antiplásticos más pequeños. Estas características correlacionan de manera variable con el grado de movilidad residencial y se relacionan a su vez (particularmente el espesor de las paredes, rugosidad de la superficie y tamaño de las inclusiones) con un mejor aprovechamiento calórico y la consecuente disminución en el consumo de combustible, importante cuando la leña es escasa (Eerkens, 2003). Por otra parte, una disminución en el espesor de las paredes disminuiría el tiempo de secado y el peso de la vasija y se puede correlacionar, asimismo, con una disminución en el tamaño de las vasijas. Todas estas son variables que facilitan el transporte de los recipientes cerámicos, que de este modo, interfieren en menor grado con la movilidad del grupo (Eerkens, 2008; Eerkens et al. 2002; Rice, 1987; Simms et al. 1997; Skibo et al. 1989; Sugrañes, 2011).

Por último, la incorporación de contenedores cerámicos en grandes cantidades, suele estar asociada a procesos de intensificación, en los que se implementan nuevas técnicas en el procesamiento de los recursos, a los fines de obtener mayor cantidad de nutrientes. En este contexto su uso se ha relacionado, especialmente, con un aumento en la proporción $e$ intensidad de las semillas procesadas y con la recuperación de la grasa animal y otros nutrientes, mediante el hervido de los alimentos (Arnold, 1985; Church \& Lyman, 2003; Eerkens, 2004; Wolverton et al. 2008). Esta tecnología también permite ampliar el rango de alimentos incorporados, facilitando su detoxificación y/o aumentando la palatabilidad, así como mediante la obtención de aceites y bebidas fermentadas (Arnold, 1985; Braun, 1983; Hayden, 1990, 1995; Hoopes, 1995).

Si bien no es posible inferir estrategias de movilidad y uso del espacio únicamente a partir de características tecnológicas, debido a que muchos factores pueden influir en la elección de uno u otro rasgo, estos estudios aportan a la discusión acerca de la presencia de rasgos distintivos en vasijas utilizadas por poblaciones móviles. En Argentina, trabajos 
en esta línea están siendo también desarrollados, a los fines de explorar las posibles relaciones entre la movilidad y el tiempo y esfuerzo invertidos en la elaboración de contenedores cerámicos (Franchetti \& Sugrañes, 2012; Sugrañes, 2011). Estos autores, sin embargo, observan que esta relación puede ser difícil de establecer en contextos en los que pudieron haberse implementado diversas estrategias de movilidad y grados de redundancia ocupacional entre los extremos opuestos de alta movilidad residencial y sedentarismo (Franchetti \& Sugrañes, 2012).

\section{La tecnología cerámica en el SE de la} Región Pampeana y el NE de Patagonia

El NE de Patagonia y el SE de la Región Pampeana fueron habitados por sociedades móviles cuya subsistencia se basó en la caza, la recolección y, en algunas áreas, la pesca. Estos grupos incorporan la tecnología cerámica hacia inicios del Holoceno tardío (Politis et al. 2001), siendo espacialmente variable la intensidad de su uso (i.e. frecuencia y tamaño de materiales cerámicos hallados en contextos arqueológicos). La alfarería en estas subregiones ha sido caracterizada como una cerámica cocida a bajas temperaturas, en atmósfera oxidante, generalmente de colores rojizo, marrón y gris y con manchas de cocción. La manufactura se realiza por enrollamiento o, en el caso de las vasijas más pequeñas, por modelado y las superficies se terminan mediante alisado o pulido, sobre el que, en ocasiones, se aplica engobe o pintura $y / 0$ se realiza una decoración incisa geométrica. Las formas (para momentos pre-hispánicos), aunque pocas veces pueden ser reconstruidas, son globulares o subglobulares abiertas y sin asas, algunas con agujeros de suspensión y con tamaños mayormente pequeños a medianos. Considerando las morfologías y tamaños representados, así como la presencia de adherencias y restos de hollín y el análisis de ácidos grasos, se ha postulado su uso en tareas de cocción, procesamiento y consumo de recursos vegetales, animales y/o ictícolas (Aldazabal, 2008; Borges Vaz et al. 2016; Di Prado, 2013, 2015; Eugenio \& Aldazabal, 2004; Frère, 2015; González, 2005; González et al. 2012; Outes, 1908; Politis et al. 2001; Prates, 2004; Prates et al. 2010; Stoessel et al. 2015).
En escala regional o macroregional la decoración cerámica presenta ciertas similitudes dadas por el tipo de motivos representados, en su mayoría geométricos, así como por las técnicas empleadas para elaborarlos (incisión e impresión). El surco rítmico formando "banderitas" es uno de los motivos con mayor dispersión espacial, encontrándoselo desde el NE de Patagonia hasta el norte de la Región Pampeana. Los motivos decorativos representados sobre los contenedores cerámicos han sido relacionados, a su vez, con aquellos representados en distintos soportes muebles (hachas y placas grabadas, huevos de Rheidae) e inmuebles (arte rupestre) (Fiore \& Borella, 2010; Carden \& Martínez, 2014). Estas similitudes han sido interpretadas como parte de un código común compartido y evidencia indirecta de la existencia de extensas redes de interacción y procesos de intercambio y/o circulación de bienes (Aldazabal, 2008; Bonomo, 2005; Di Prado 2013, 2015; González 2005; González \& Frère, 2010 Politis et al. 2001). Por otra parte, la presencia de motivos y técnicas similares se ve acompañada por una alta diversidad en sus combinaciones y por heterogeneidad en las pastas cerámicas, con variaciones en el tipo y frecuencia de sus inclusiones (el tiesto molido, por ejemplo, muestra una alta proporción al norte de las sierras de Tandilia y muy baja hacia el sur de estas). Las pastas a su vez, muestran cierta correspondencia con los sedimentos locales, todo lo cual ha llevado a proponer el uso de fuentes de aprovisionamiento de arcillas de distinto origen, para una producción local a baja escala y supeditada a los requerimientos del grupo doméstico (Aldazabal et al. 2015; Di Prado, 2015; Eugenio \& Aldazábal, 2013; González de Bonaveri et al. 2000; Madrid, 1997; Mazzanti \& Porto López, 2007), en tanto las redes de larga distancia pudieron funcionar como un mecanismo más para la circulación de este tipo de contenedores (Eugenio \& Aldazábal, 2013; Mazzanti \& Porto López, 2007). La hipótesis de una manufactura local se ve reforzada por la presencia de masas de arcilla sin indicios de cocción en el NE de Patagonia (Di Prado, 2013; Prates et al. 2010) y en la Depresión del Río Salado (Frère, 2015; González, 2005).

Tanto en el SE de la Región Pampeana como en el NE de Patagonia, el material cerámico 
es escaso y con un alto grado de fragmentación (Catella \& Saghessi, 2007; Eugenio \& Aldazábal, 2004; Madrid, 1997; Outes, 1908; Prates, 2004; Vignati, 1931). Considerando esta situación, se ha planteado que este tipo de materiales tuvo una distribución restringida, que pudo estar relacionada con sistemas de intercambio $y / 0$ de prestigio de algunos grupos minoritarios (Aldazabal, 2008). Por otra parte, Eugenio et al. (1987-1988) y Crivelli Montero (1993-1994) propusieron que la falta de leña en muchos sectores de la provincia de Buenos Aires -particularmente en el área Interserranapudo haber incidido sobre la baja frecuencia de los materiales cerámicos. En tal sentido, en dicha zona los huesos son el combustible de la mayor parte de los fogones arqueológicos, en tanto los datos etnohistóricos mencionan el uso de duraznillo (arbusto con ramas de escaso diámetro y que producen abundante humo) y, cuando la leña estaba ausente, hueso, cebo y bosta (Crivelli Montero, 1993-1994). Considerando este factor, las zonas aptas para la producción cerámica se limitarían a los ambientes con abundancia de combustible, como las selvas mixtas o marginales, la provincia del Espinal, las inmediaciones de Ventania, donde crece Salix Humboldiana (Cabrera, 1971) y los sectores de Tandilia en los que abunda el curro (Colletia cruciata) (Crivelli Montero, 1993-1994; Eugenio et al. 1987-1988). En cambio, Politis y Madrid (2001) consideraron que la leña no habría sido un recurso determinante debido a que las bajas temperaturas a las que se coció la cerámica pueden ser alcanzadas mediante la utilización de arbustos. Por otra parte, la escasa frecuencia relativa en el SE de la Región Pampeana ha sido interpretada como consecuencia de estrategias de movilidad, con un corto tiempo de ocupación de los sitios, que redundaría en la fabricación de la cerámica para ser utilizada de manera ocasional o bien con un carácter altamente conservado (Politis et al. 2001).

\section{METODOLOGÍA}

Los materiales cerámicos de la cuenca del Arroyo Chasicó fueron analizados macroscópica y sub-macroscópicamente teniendo en cuenta aspectos tecnológicos, morfológicos y estilísticos $y$, complementariamente, categorías que aportan información acerca del estado de la muestra y los procesos de formación del registro. Para esto se siguieron los lineamientos propuestos, entre otros, por Shepard (1956), Rice (1987), Rye (1994), P.C.R.G. (1995), Orton et al. (1997) y la Primera Convención Nacional de Antropología (1966).

Macroscópicamente se consignaron, con calibre de corredera, las dimensiones de los fragmentos (largo y ancho máximo, así como el espesor en 4 sectores) y se realizaron remontajes en todos aquellos casos en que fue posible. Se analizó la regularidad o irregularidad de la fractura fresca, se determinó la dureza medida en ambas superficies mediante la utilización de la escala de dureza relativa de Mohs (Orton et al. 1997), y se consignó el color en fractura fresca en 5 sectores: núcleo, márgenes (externa e interna) y superficies (externa e interna), utilizando la propuesta del P.C.R.G. (1995), consistente en emplear cuatro categorías basadas en espectros cromáticos: espectro 1: naranja-marrón-rojo; espectro 2: rosa claro-amarillo-blanco; espectro 3: blanco; espectro 4: gris-negro. Las técnicas de manufactura fueron identificadas, a partir de rasgos como la presencia de ondulaciones en la superficie o de puntos débiles (Orton et al. 1997). Se analizó también el tratamiento de la superficie, características y localización de la decoración y se estimó, en aquellos casos en que el tamaño de los fragmentos lo posibilitó, la forma y dimensiones de la vasija, así como el tipo de borde y/o base, y el tipo de labio. El estado de conservación de la muestra se evaluó consignándose, en cada tiesto, la depositación de sales, el grado de exfoliación y el grado de abrasión o rodamiento. La exfoliación y la abrasión fueron evaluados considerando 4 estadios definidos, en el primer caso, por el porcentaje de la superficie con evidencias de exfoliación (sin exfoliación, exfoliación leve o grado 1 , exfoliación media o grado 2 y exfoliación alta o grado 3) y, en el segundo, por el redondeamiento de los bordes (considerando los criterios de Skibo, 1987 y empleados en la Región Pampeana por Ozán, 2010 y, con algunas modificaciones por Catella \& Saghessi, 2007). También se evaluó el grado de fragmentación de la muestra en función del tamaño de los tiestos que la conforman. Por último, se relevaron las alteraciones generadas por el uso presentes en las superficies interna y externa, buscando identificar adherencias (i.e. hollin, 
residuos de cocción), manchas por exposición al fuego y zonas de deterioro producto de la acción humana (Skibo, 1992).

Sub-macroscópicamente se estudiaron, mediante la utilización de una lupa binocular Hokenn con aumentos de entre 10X y 40X, las características de la pasta en las superficies y en fractura fresca, considerando las siguientes variables: 1) densidad de las inclusiones en función de cinco categorías basadas en los gráficos de estimación de porcentaje de las inclusiones de Matthew et. al. (1991), sin discriminar por tipo; 2) selección de las inclusiones, considerándose cinco categorías (muy escasa, escasa, moderada, buena, muy buena) caracterizadas sobre la base de la homogeneidad en el tamaño de las partículas; 3) forma de las inclusiones, en relación con su grado de angulosidad o redondez; 4) tipo de inclusiones, en aquellos casos en que, por su tamaño, fue posible identificarlas con lupa binocular; 5) regularidad o irregularidad en la distribución de las inclusiones; 6) tamaño máximo de las inclusiones.

Por último, se generaron modelos espaciales y estadísticos que pusieron en relación la información obtenida para la cuenca del arroyo Chasicó, con aquella generada por otros investigadores (i.e. datos secundarios) para el centroeste de Argentina. El análisis de datos secundarios implica, típicamente, el estudio de información recolectada en forma primaria (i.e. original) por uno o varios investigadores a lo largo del tiempo y que se organiza en bases, especialmente creadas con la finalidad de responder a interrogantes bien definidos que, generalmente, son diferentes de aquellos que inicialmente motivaron su obtención (Andrews et al. 2012; Devine, 2003; Fielding, 2004). A partir de la información recolectada en 102 sitios arqueológicos georreferenciados se realizaron, mediante sistemas de información geográfica (SIG), dos modelos espaciales continuos (superficies continuas en formato raster). Cabe aclarar que esta clase de modelos contiene información tanto sobre los fenómenos sociales o poblacionales del pasado, como acerca de los factores que condicionan o posibilitan la conservación, recuperación e interpretación de sus correlatos materiales (i.e. procesos tafonómicos, estrategias de muestreo y análisis arqueológico) (Barrientos et al. 2015).
Para la generación de los modelos continuos se emplearon: 1- frecuencias absolutas; 2- frecuencias relativas. Las frecuencias relativas fueron estimadas por medio de un índice de cerámica, calculado como el total de fragmentos cerámicos/el total de artefactos líticos de un sitio. Si bien este índice puede presentar ciertas ambigüedades, dado que la frecuencia de materiales líticos puede variar en función de diversos factores (i.e. disponibilidad local de rocas, funcionalidad del sitio, duración y/o redundancia de ocupación), esta es la única información disponible en todos los sitios del centro-este de Argentina que nos permite relativizar la frecuencia de materiales cerámicos con respecto a la densidad de materiales de cada sitio. Los modelos consisten en mapas distribucionales continuos, generados mediante la técnica de interpolación Inverse Distance Weighted (IDW), con un radio de búsqueda de cinco puntos y un valor $\mathrm{p}=2$ (parámetro power). IDW es un método de interpolación inexacto que puede ser forzado a ser exacto (i.e. genera una estimación que representa, de manera más o menos precisa, los valores observados en los puntos muestreados), local (i.e. aplica un mismo algoritmo a subconjuntos de datos muestrales, seleccionados a partir de un radio de búsqueda predeterminado alrededor del punto que será estimado) y determinista (i.e. realiza una suposición general acerca del carácter de la superficie a interpolar, sin emplear elementos probabilísticos) (Burrough \& McDonnell, 1998). En tal sentido, una de sus principales ventajas radica en que permite captar variaciones de pequeño rango espacial, no siendo necesario vincular los datos a un modelo estadístico particular, por lo que permite trabajar con muestras regular o irregularmente distribuidas en el espacio (Burrough \& McDonnell, 1998).

El análisis estadístico se realizó considerando algunas de las características tecnológicas analizadas en los materiales de la cuenca del arroyo Chasicó y sobre las cuales se pudo relevar información para las áreas Tandilia (Mazzanti \& Porto López, 2007), Interserrana (Madrid, 1997), Ventania (Madrid, 1997 y datos presentados en este trabajo) y Sur (datos presentados en este trabajo). Dado que la información es diversa, se consideraron sólo aquellas variables para las que se contaba con información en todas las áreas. Las variables 
empleadas fueron; a) espesor de los fragmentos, b) porcentaje de inclusiones y c) textura. En todos los casos, se obtuvo el valor de la mediana de cada distribución, a partir del cual se realizó un análisis de cluster, utilizando el método Ward's con distancias euclideanas (Statistica 8).

\section{RESULTADOS}

La muestra total de materiales cerámicos de la cuenca del arroyo Chasicó consiste en 87 fragmentos, procedentes de las diferentes subcuencas. Esta baja proporción de material cerámico en relación con otro tipo de materiales como los artefactos líticos, se corresponde con lo descrito para la mayoría de los sitios ubicados en el centro y sur de la Región Pampeana y en el NE de Patagonia.

\section{La Montaña sitio 1 (LM1)}

Los fragmentos cerámicos de la subcuenca superior fueron recuperados a partir de excavaciones sistemáticas realizadas por F. Oliva en el sitio 1 de la localidad arqueológica La Montaña. Estos se encontraron en asociación con artefactos líticos, entre ellos dos puntas de proyectil triangulares pequeñas y elementos óseos asignables a Lama guanicoe y Ozotoceros bezoarticus. Concordantemente con el tipo de materiales recuperados, dos fechados radiocarbónicos ubican a este sitio hacia finales del Holoceno tardío, entre ca. 300 y 700 años $C^{14}$ AP (Catella, 2014; Oliva, 2000, 2017; Oliva et al. 2000).

La colección cerámica consiste en 30 fragmentos recuperados entre los niveles 6 y 11 de las cuadrículas 1,2 y 3 . La muestra no presenta depositación de sales, pero su grado de fragmentación es alto, estando conformada por tiestos que no superan los $18 \mathrm{~cm}^{2}$ de superficie y más de la mitad de los fragmentos con dimensiones de entre $0,6 \mathrm{~cm}^{2}$ y $4 \mathrm{~cm}^{2}$. A pesar de esta situación, o como consecuencia de la misma, los bordes de los tiestos se encuentran sólo levemente redondeados (grado 1) y sus superficies sin evidencias de exfoliación, o con una exfoliación leve (grado 1).

La fractura es, en todos los casos, irregular y las pastas son blandas, con dureza en la escala de Mohs de entre 3 y 4 (Tabla 1), lo que indica, si bien no de manera directa ya que tanto fractura como dureza dependen de diversos factores, una cocción a bajas temperaturas. A su vez, la muestra se encuentra conformada por fragmentos con colores dentro del espectro 2 (rosa claro-amarillo-blanco) y del espectro 4 (gris-negro), con algunos fragmentos mostrando colores del espectro 1 (naranja-marrónrojo) (Tabla 1). Esta distribución de colores está indicando el predominio de condiciones de cocción en atmósfera oxidante incompleta, tanto de pastas con bajo contenido de hierro (en el caso de las pastas con colores del espectro 2) como de pastas con mayor contenido de este mineral. La presencia de fragmentos negros en toda la sección puede ser indicador, o bien de su cocción en una atmósfera reductora o transformada en reductora en momentos finales de la cocción por medio del agregado de, por ejemplo, leña verde o estiércol, o bien una cocción breve que no fue suficiente para producir la oxidación de la pasta (Orton et al. 1997; P.C.R.G., 1995). En cuanto a las huellas de uso, tres tiestos presentan restos de hollín en la superficie externa.

Pudo observarse la pasta con lupa binocular en 28 de los fragmentos recuperados, dado que los dos restantes poseen tamaños muy pequeños. Las pastas presentan inclusiones con distribución regular y densidades que oscilan generalmente entre $4 \%$ y $20 \%$, con variada selección (Tabla 2). En todas las muestras analizadas se observó la presencia de inclusiones sub-redondeadas, las cuales se combinan con inclusiones sub-angulares y/o redondeadas (Tabla 2). Aquellas inclusiones que pudieron ser identificadas consisten, según su abundancia, en cuarzo, mica y rocas negras, blancas y marrones indeterminadas, a lo que se agrega la probable presencia de tiesto molido en un fragmento.

En relación con el tratamiento de las superficies, se encuentran fragmentos alisados y tosco alisados en ambas superficies y sólo dos fragmentos pulidos (Catella, 2004) (Tabla 3). El espesor promedio de los tiestos oscila entre $2,25 \mathrm{~mm}$ y 6,75 mm. Dada la fragmentación de la muestra, no fue posible reconstruir formas completas, pero se recuperaron un total de cinco fragmentos de borde correspondientes, en función del color y selección, densidad y tamaño de las inclusiones, a por lo menos dos vasijas diferentes. Se trata, de 
Tabla 1. Principales características tecnológicas de los materiales cerámicos.

\begin{tabular}{|c|c|c|c|c|c|}
\hline & & LM1 & $\mathrm{LCH}$ & col SM & LCHA \\
\hline \multirow{3}{*}{ Fractura } & Regular & 0 & 2 & 0 & 6 \\
\hline & Irregular & 30 & 9 & 9 & 29 \\
\hline & Indeterminado & 0 & 2 & 0 & 0 \\
\hline \multirow{4}{*}{ Dureza } & 2 & 0 & 0 & 0 & 7 \\
\hline & 3 & 12 & 8 & 9 & 25 \\
\hline & 4 & 14 & 3 & 0 & 1 \\
\hline & Indeterminado & 4 & 2 & 0 & 2 \\
\hline \multirow{4}{*}{$\begin{array}{c}\text { Color en } \\
\text { superficie } \\
\text { externa }\end{array}$} & Espectro 1 & 0 & 8 & 4 & 27 \\
\hline & Espectro 2 & 19 & 0 & 0 & 0 \\
\hline & Espectro 4 & 10 & 5 & 5 & 8 \\
\hline & Indeterminado & 1 & 0 & 0 & 0 \\
\hline \multirow{3}{*}{$\begin{array}{l}\text { Color en } \\
\text { margen } \\
\text { externa }\end{array}$} & Espectro 1 & 0 & 5 & 4 & 19 \\
\hline & Espectro 2 & 18 & 0 & 0 & 0 \\
\hline & Espectro 4 & 12 & 8 & 5 & 16 \\
\hline \multirow{3}{*}{$\begin{array}{c}\text { Color en } \\
\text { núcleo }\end{array}$} & Espectro 1 & 1 & 5 & 3 & 11 \\
\hline & Espectro 2 & 16 & 0 & 0 & 1 \\
\hline & Espectro 4 & 13 & 8 & 6 & 23 \\
\hline \multirow{3}{*}{$\begin{array}{c}\text { Color en } \\
\text { margen } \\
\text { interna }\end{array}$} & Espectro 1 & 2 & 1 & 3 & 6 \\
\hline & Espectro 2 & 14 & 0 & 0 & 1 \\
\hline & Espectro 4 & 14 & 12 & 6 & 28 \\
\hline \multirow{4}{*}{$\begin{array}{l}\text { Color en } \\
\text { superficie } \\
\text { interna }\end{array}$} & Espectro 1 & 1 & 0 & 1 & 12 \\
\hline & Espectro 2 & 7 & 0 & 0 & 0 \\
\hline & Espectro 4 & 21 & 13 & 8 & 23 \\
\hline & Indeterminado & 1 & 0 & 0 & 0 \\
\hline
\end{tabular}

labios convexos y bordes rectos, que por su pequeño tamaño no permitieron determinar el diámetro de boca (Tabla 4). La decoración consiste en líneas incisas muy finas conformando motivos geométricos sobre la superficie externa (Fig. 2), en algunos casos con remanentes de pintura roja conservada dentro de los poros y de las líneas de incisión. También se observaron dos tiestos con restos de pintura roja en la superficie interna (Tabla 4).

\section{Laguna Los Chilenos (LCH)}

Laguna Los Chilenos es otra localidad arqueológica localizada en la subcuenca superior, pero en este caso ya en un ambiente de llanura, limitando con la subcuenca media. El material cerámico proviene de dos sitios localizados sobre su margen sudeste. El sitio 1 (LCH1) se encuentra conformado por dos entierros primarios y un entierro secundario múltiple, datado en $470 \pm 40$ año $C^{14}$ AP (Barrientos et al. 2002) (corregido por fraccionamiento isotópico en ca 600 años $C^{14} \mathrm{AP}$; Catella, 2014). En este sitio se recuperaron siete fragmentos cerámicos en la cuadrícula 2 y uno en la cuadrícula 5 junto a algunos pocos artefactos líticos, cuentas circulares de valva y un fragmento de valva de Adelomelon sp. (Barrientos, 1997; Barrientos et al. 2002). Un noveno fragmento fue recuperado en el sitio 2 ( $\mathrm{LCH} 2$ ), localizado 500 $\mathrm{m}$ al sudoeste del primero, donde se recuperaron 
Tabla 2. Características de las pastas observadas con lupa binocular. En el caso de las formas los totales son mayores debido a que diferentes formas pueden encontrarse en un mismo fragmento

\begin{tabular}{llccc}
\hline & & LM1 & LCH & LCHA \\
\hline \multirow{5}{*}{ Distribución } & Regular & 27 & 9 & 32 \\
& Irregular & 1 & 4 & 0 \\
& Indeterminado & 2 & 0 & 3 \\
\hline \multirow{5}{*}{ Densidad } & $03 \%-10 \%$ & 16 & 7 & 4 \\
& $10 \%-20 \%$ & 11 & 5 & 6 \\
& $20 \%-30 \%$ & 1 & 1 & 19 \\
& $30 \%-40 \%$ & 0 & 0 & 3 \\
& Indeterminado & 2 & 0 & 3 \\
\hline \multirow{5}{*}{ Selección } & Muy escasa/escasa & 9 & 0 & 3 \\
& Moderada & 11 & 0 & 13 \\
& Buena/muy buena & 8 & 13 & 16 \\
& Indeterminado & 2 & 0 & 3 \\
\hline \multirow{5}{*}{ Forma } & Redondeada & 11 & 4 & 5 \\
& Subredondeada & 28 & 13 & 29 \\
& Angular & 1 & 2 & 9 \\
& Subangular & 19 & 7 & 4 \\
\hline
\end{tabular}

Tabla 3. Tratamiento de las superficies en LM1. TSE=tratamiento de la superficie externa; TSI=tratamiento de la superficie interna.

\begin{tabular}{lcccccc}
\hline TSI & Tosco & Tosco-alisado & Alisado & Pulido & Indeterminado & Total \\
\hline Tosco & 0 & 0 & 0 & 0 & 0 & 0 \\
Tosco-alisado & 0 & 9 & 2 & 0 & 0 & 11 \\
Alisado & 0 & 0 & 15 & 0 & 0 & 15 \\
Pulido & 0 & 0 & 0 & 2 & 0 & 2 \\
Indeterminado & 0 & 0 & 0 & 0 & 2 & 2 \\
\hline Total & 0 & 9 & 17 & 2 & 2 & 30 \\
\hline
\end{tabular}

también, artefactos líticos, fragmentos de voluta de Adelomelon sp. y restos óseos de guanaco y venado a partir de los cuales se realizó un fechado que lo ubica cronológicamente en ca. 2.300 años $C^{14}$ AP (Catella, 2014; Oliva, 2017). Por último, 4 fragmentos fueron recolectados en superficie, en el sector de playa ubicado entre los dos sitios mencionados, quedando la muestra total analizada conformada por 13 fragmentos.

Todos los fragmentos recuperados en estratigrafía presentan un bajo grado de abrasión y exfoliación (grado 1), pero un alto nivel de fragmentación, evidenciado en que sólo el fragmento recuperado en el sitio 2 supera los tres $\mathrm{cm}^{2}$. Los tiestos recuperados en superficie también presentan un alto grado de fragmentación, a lo que se suma mayor abrasión de los bordes (grado 2) y alta exfoliación de las superficies (grado 2 a grado 4). La dureza varía entre 3 y 4 y la fractura es en la mayor parte de los casos irregular (Tabla 
1). Tanto la pasta blanda como la fractura irregular predominante estarían indicando la cocción de las vasijas cerámicas a bajas temperaturas (Orton et al. 1997). Los colores representados consisten en el negro-gris en toda la sección o bien combinado con naranja-marrón en la sección exterior (Tabla 1), consistentes con condiciones de cocción incompleta en atmósfera oxidante (P.C.R.G., 1995).

Las pastas observadas con lupa binocular presentan entre $2 \%$ y $30 \%$ de antiplástico distribuido tanto regular como irregularmente, con formas sub-redondeadas, redondeadas y subangulares, y con una selección entre buena y muy buena (Tabla 2), donde ninguna partícula supera los $0,5 \mathrm{~mm}$ de diámetro. Entre los antiplásticos que pudieron ser identificados se encuentran cuarzo (en todas las pastas) y tres fragmentos con posible tiesto molido, a las que se suman rocas

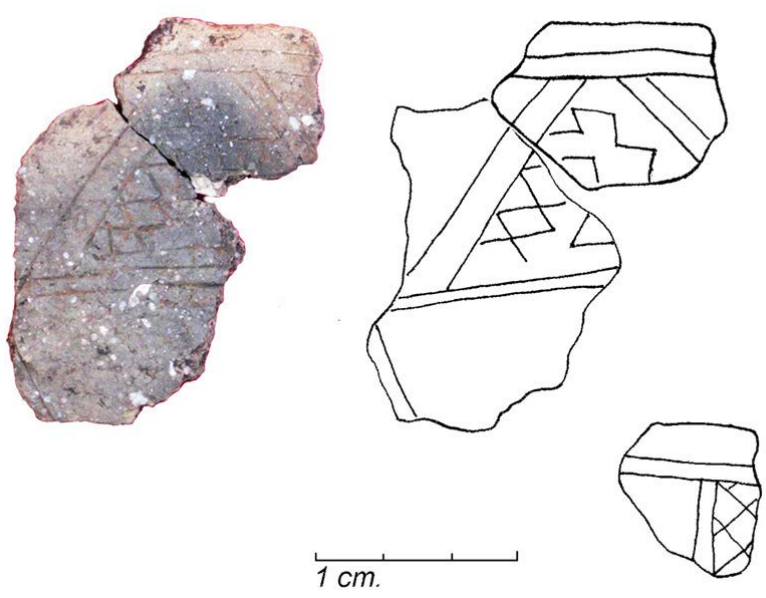

Fig. 2. Diseños decorativos presentes en la cerámica de LM1.

Tabla 4. Forma y decoración.

\begin{tabular}{|c|c|c|c|c|c|}
\hline & & LM1 & $\mathrm{LCH}$ & col SM & LCHA \\
\hline \multirow{3}{*}{ Tipo de Borde } & Recto & 5 & 0 & 7 & 6 \\
\hline & Evertido & 0 & 1 & 0 & 0 \\
\hline & Levemente invertido & 0 & 0 & 0 & 1 \\
\hline \multirow{2}{*}{$\begin{array}{l}\text { Espesor del } \\
\text { borde (mm) }\end{array}$} & Mínimo & 3 & 4 & 4 & 3,5 \\
\hline & Máximo & 5 & 4 & 5,5 & 6 \\
\hline \multirow{2}{*}{ Tipo de labio } & Recto & 0 & 0 & 0 & 0 \\
\hline & Convexo & 5 & 1 & 7 & 7 \\
\hline \multirow{6}{*}{$\begin{array}{c}\text { Diámetro } \\
\text { de boca }(\mathrm{mm})\end{array}$} & $6-8$ & 0 & 0 & 1 & 0 \\
\hline & 15 & 0 & 1 & 0 & 0 \\
\hline & $20-25$ & 0 & 0 & 0 & 2 \\
\hline & $12-24$ & 0 & 1 & 0 & 0 \\
\hline & $>15$ & 0 & 0 & 4 & 0 \\
\hline & Indeterminado & 5 & 0 & 2 & 4 \\
\hline \multirow{3}{*}{ Decoración incisa } & Superficie externa & 11 & 0 & 1 & 2 \\
\hline & Superficie interna & 0 & 0 & 0 & 1 \\
\hline & Labio & 0 & 1 & 0 & 1 \\
\hline \multirow{2}{*}{ Pintura/engobe } & Superficie externa & 4 & 7 & 1 & 1 \\
\hline & Superficie interna & 2 & 0 & 0 & 0 \\
\hline \multirow{3}{*}{$\begin{array}{l}\text { Espesor del } \\
\text { cuerpo }(\mathrm{mm})\end{array}$} & Mínimo & 2,25 & 3 & 4,5 & 3,87 \\
\hline & Máximo & 4,68 & 7 & 7,2 & 10,7 \\
\hline & Mediana & 5 & 6 & 6 & 5,87 \\
\hline
\end{tabular}


negras, marrones y blancas indeterminadas.

Los tiestos presentan las superficies externa e interna con distintas combinaciones de pulido, alisado y tosco alisado, con engobe rojo en aquellos fragmentos con la superficie externa pulida (Tabla 5). La muestra se encuentra conformada por fragmentos de cuerpo cuyo espesor oscila entre 3 $\mathrm{mm}$ y $7 \mathrm{~mm}$. Sólo se recuperó un borde evertido, con labio convexo e incisiones rectas paralelas sobre éste, que permitió estimar un diámetro de boca de entre $12 \mathrm{~cm}$ y $24 \mathrm{~cm}$ (Tabla 4) (Catella, 2004).

\section{Colección San Martín (col. SM)}

En la subcuenca media, los materiales cerámicos proceden de la Colección San Martín del Museo Regional Chasicó. Esta colección se encuentra conformada por nueve fragmentos recolectados por la Prof. Cinquini en inmediaciones del sitio 1 de la localidad arqueológica San Martín, si bien probablemente no se correspondan a la misma ocupación, ya que no se observaron materiales cerámicos durante la excavación (Oliva et al. 1991; Catella, 2014). En este sector del arroyo Chasicó se registraron materiales arqueológicos sobre las distintas terrazas, en una extensión de aproximadamente $1400 \mathrm{~m}$ lineales, lo que junto a la presencia de artefactos de molienda y un posible escondrijo de artefactos líticos, llevan a estimar su utilización en reiterados momentos. Por tratarse de colecciones estudiadas en el mismo museo en que se encuentran depositadas, donde no se cuenta con una lupa binocular para hacer las observaciones de pastas, las características de las inclusiones no fueron analizadas en este caso.

La muestra presenta pastas blandas, con fractura irregular y colores correspondientes al espectro negro-gris y naranja-marrón-rojo en toda la sección o con variaciones en sus distintos sectores (Tabla 1) características que, también en este caso, estarían indicando su cocción en una atmósfera oxidante incompleta, a baja temperatura. Los tratamientos de la superficie representados son el tosco, tosco-alisado y alisado, no habiéndose recuperado ningún fragmento pulido (Tabla 6). El espesor de los tiestos oscila entre 4,5 mm y 7,2 $\mathrm{mm}$, sólo uno de los tiestos muestra decoración incisa y pintura roja sobre la superficie externa. Los bordes son de tipo recto y con labio convexo, a partir de los cuales se proyectaron dos diámetros de boca diferentes, uno de entre $6 \mathrm{~cm}$ y $8 \mathrm{~cm}$ y otro mayor a $15 \mathrm{~cm}$ (Tabla 4).

\section{Laguna Chasicó (LCHA)}

En la subcuenca inferior, el material cerámico analizado procede de la margen sudoeste de la laguna Chasicó. Se trata de 35 tiestos, dos de ellos recuperados por el Sr. Peluso (habitante de la localidad de Chapalcó) en inmediaciones del sitio 2 (LCHA2) y del sitio 3 (LCHA3) y los restante 33 provenientes de recolecciones superficiales sistemáticas llevadas a cabo en el sitio 1 (LCHA1) $(n=4)$, en LCHA $2(n=19)$ y en LCHA $3(n=10)$, distantes uno del otro menos de $2 \mathrm{~km}$ en línea recta (Catella, 2014). Considerando la cercanía y, dada la escasa cantidad del registro cerámico y la similitud de

Tabla 5. Tratamiento de las superficies en LCH. TSE=tratamiento de la superficie externa;

TSI=tratamiento de la superficie interna.

\begin{tabular}{lcccccc}
\hline TSI & Tosco & $\begin{array}{c}\text { Tosco- } \\
\text { alisado }\end{array}$ & Alisado & Pulido & Indeterminado & Total \\
\hline Tosco & 0 & 0 & 0 & 0 & 0 & 0 \\
Tosco-alisado & 0 & 2 & 0 & 0 & 0 & 2 \\
Alisado & 0 & 0 & 3 & 2 & 0 & 5 \\
Pulido & 0 & 0 & 0 & 5 & 0 & 5 \\
Indeterminado & 0 & 0 & 0 & 0 & 1 & 1 \\
\hline Total & 0 & 2 & 3 & 7 & 1 & 13 \\
\hline
\end{tabular}


Tabla 6. Tratamiento de las superficies en col SM. TSE=tratamiento de la superficie externa; TSI=tratamiento de la superficie interna.

\begin{tabular}{lccccc}
\hline TSI & TSE & Tosco-alisado & Alisado & Pulido & Total \\
\hline Tosco & 0 & 0 & 0 & 0 & 0 \\
Tosco-alisado & 2 & 1 & 3 & 0 & 6 \\
Alisado & 0 & 0 & 3 & 0 & 3 \\
Pulido & 0 & 0 & 0 & 0 & 0 \\
\hline Total & 2 & 1 & 6 & 0 & 9 \\
\hline
\end{tabular}

los fragmentos recuperados, la información será presentada en conjunto, realizando las distinciones que sean necesarias. Cabe destacar que, en este caso, las pastas no fueron analizadas en los fragmentos de la colección Peluso, por no contarse con lupa binocular cuando fueron estudiadas. La muestra presenta un estado de conservación variable, con depositación de sales en la mayor parte de los tiestos y predominio de los fragmentos con abrasión y exfoliación leve (grado $1=22$ ). No se registró ningún fragmento con alto grado de abrasión, observándose sólo dos con alto grado de exfoliación, en tanto los tiestos restantes presentan un grado medio de abrasión y exfoliación, indicando un tiempo de exposición corto y un bajo grado de transporte hídrico.

En relación con las variables tecnológicas indicadoras del modo de manufactura, la fractura es mayoritariamente irregular y la dureza oscila entre 2 y 4 . Los colores de pasta corresponden al espectro 1 (naranja-marrón-rojo) y al espectro 4 (gris-negro), ya sea de forma homogénea o alternando en los distintos sectores del perfil (Tabla 1). Estas características indican una cocción a baja temperatura en una atmósfera oxidante que, al menos en la mayor parte de los casos, habría resultado incompleta. La técnica de manufactura pudo ser inferida como enrrollamiento anular por la presencia de grietas, surcos y/o costuras en 10 fragmentos $y$, en dos casos, pudo establecerse que los rollos utilizados tendrían, entre $17 \mathrm{~mm}$ y 18 $\mathrm{mm}$ de ancho.

Observados en lupa binocular, los cortes frescos presentan pastas compuestas por entre un $20 \%$ y $30 \%$ de inclusiones, con algunos casos por debajo y otros por encima de estos valores (Tabla
3). La porción no plástica tiene una distribución regular con partículas sub-redondeadas en casi la totalidad de los fragmentos, acompañadas por partículas angulares, redondeadas $\mathrm{y} / \mathrm{o}$ sub-angulares (Tabla 2). La selección es entre moderada y buena a muy buena (Tabla 2), lo que se correlaciona con el pequeño tamaño de las inclusiones, que sólo en seis tiestos superan el milímetro de diámetro. Entre las inclusiones identificadas se encuentran el cuarzo, presente en todas las pastas, cuarcita, mica y dos fragmentos con probable tiesto molido. También se observaron rocas de colores marrón, negro y blanco, que no pudieron determinarse.

El tratamiento de las superficies es predominantemente alisado $y$ en menor proporción tosco-alisado y pulido (Tabla 7). El espesor de los fragmentos presenta una mayor variación que en otros sitios, con las piezas más espesas recuperadas en LCHA2 y LCHA3. En relación con la forma que pudieron tener las vasijas, se recuperaron un total de siete fragmentos de borde, uno recolectado por el Sr. Peluso y los otros seis por la autora. Se trata de bordes con espesores entre $3,5 \mathrm{~mm}$ y $6 \mathrm{~mm}$, rectos o levemente invertidos y con labios convexos, cuya proyección de las bocas indica diámetros entre 15 $\mathrm{cm}$ y $25 \mathrm{~cm}$. Dos fragmentos presentan agujeros (uno cada uno), posiblemente de suspensión, localizados a $25 \mathrm{~mm}$ y $50 \mathrm{~mm}$ del borde. Pudo realizarse la reconstrucción de la forma de una vasija a partir de un fragmento que comprende un sector de borde, un porcentaje del cuerpo y se extiende hasta el inicio de la base. Esta consiste en un cuenco abierto de contorno simple, con un diámetro de boca de entre $17 \mathrm{~cm}$ y $18 \mathrm{~cm}$ y una altura de $13 \mathrm{~cm}$ aproximadamente. Posee 
Tabla 7. Tratamiento de las superficies en los sitios localizados sobre la laguna Chasicó.

TSE=tratamiento de la superficie externa; TSI=tratamiento de la superficie interna.

\begin{tabular}{|c|c|c|c|c|c|c|}
\hline TSI & Tosco & Tosco-alisado & Alisado & Pulido & Indeterminado & Total \\
\hline Tosco & 0 & 0 & 0 & 0 & 0 & 0 \\
\hline Tosco-alisado & 2 & 4 & 0 & 0 & 0 & 6 \\
\hline Alisado & 0 & 4 & 12 & 5 & 5 & 26 \\
\hline Pulido & 0 & 0 & 1 & 2 & 0 & 3 \\
\hline Total & 2 & 4 & 13 & 7 & 5 & 35 \\
\hline
\end{tabular}

uno de los agujeros de suspensión, o remiendo, mencionados, de sección bicónica, localizado a cinco $\mathrm{cm}$ del borde, cuyo diámetro no pudo ser estimado, por estar ubicado sobre el borde de fractura (Fig. 3). Por último, tres fragmentos muestran residuos de cocción en la superficie interna y otros dos presentan restos de hollín en la superficie externa.

La decoración es escasa, sólo algunos fragmentos muestran evidencias de engobe o pintura roja en la superficie externa. La decoración incisa se encuentra presente en los fragmentos recolectados
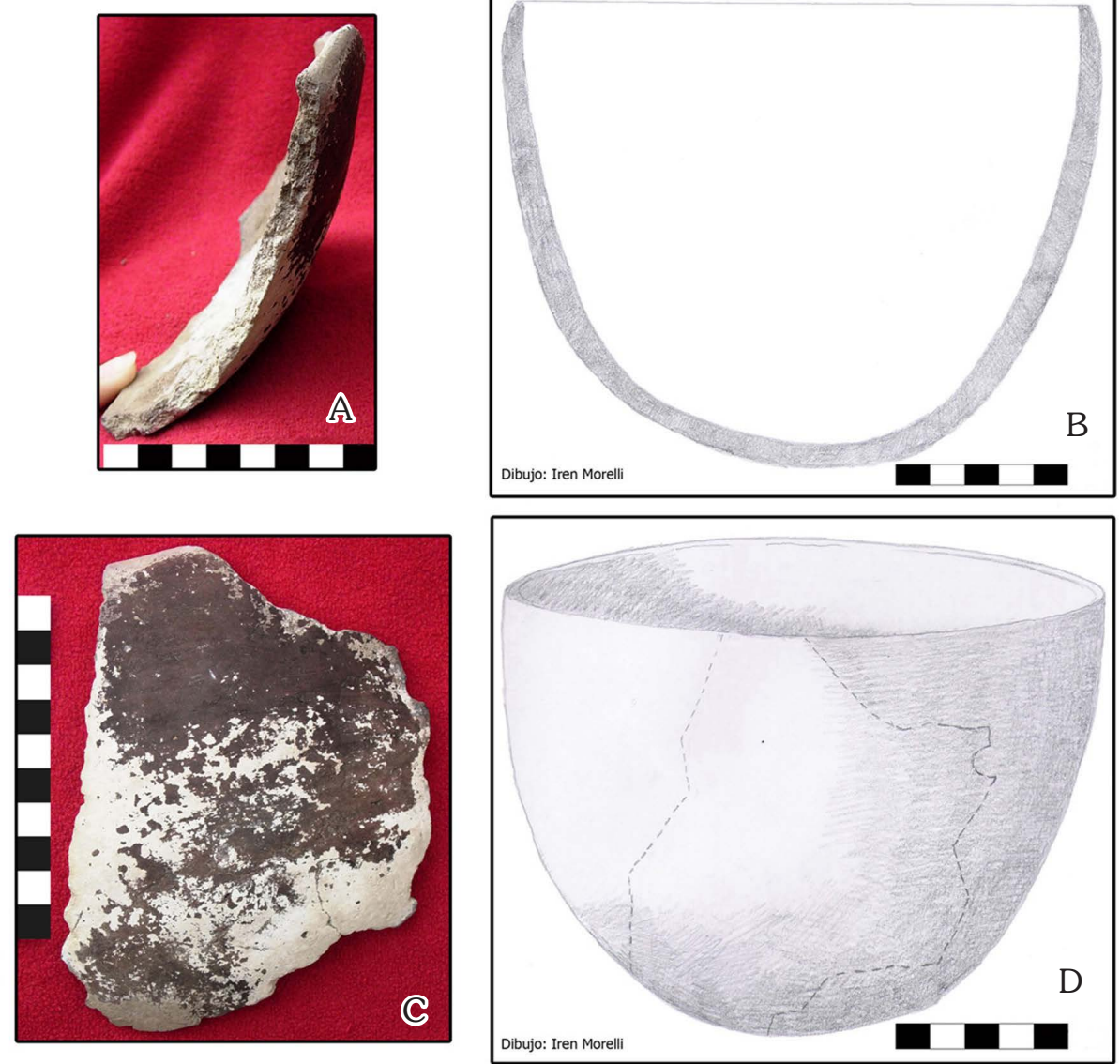

Fig. 3. Reconstrucción de la forma de la vasija a partir de un fragmento que comprende un sector de borde, un porcentaje del cuerpo y se extiende hasta el inicio de la base. A. perfil del fragmento; B. reconstrucción del perfil de la vasija; C. vista de la superficie externa del fragmento; D. reconstrucción de la forma de la vasija. 
por el Sr. Peluso, los que además de engobe rojo en la superficie externa han sido decorados con motivos geométricos realizados mediante incisión $e$ impresión. Uno de ellos presenta decoración incisa realizada por surco rítmico en la superficie externa, en tanto en el otro caso se utilizó tanto surco rítmico como impresión con un elemento circular hueco (i.e. caña o vértebra de pez). En este último, la decoración más elaborada se encuentra en la superficie externa, pero también se registró un arreglo lineal de impresiones circulares sobre la cara interna, cerca del borde, e incisiones lineales sobre el labio (Fig. 4).

\section{LA TECNOLOGÍA CERÁMICA ANALIZADA EN DIFERENTES ESCALAS}

\section{La tecnología cerámica en la} cuenca del arroyo Chasicó

En el área de estudio la tecnología cerámica se encuentra representada en muy baja frecuencia $y$, generalmente, con un alto grado de fragmentación. Más del $90 \%$ de la muestra presenta algún grado de abrasión o exfoliación, encontrándose a su vez, en la laguna Chasicó, un amplio porcentaje de fragmentos con depositación de sales (generalmente carbonato de calcio). La abrasión y exfoliación, aunque bajas, pueden generar el desgaste y desprendimiento de las partículas que se encuentran en la superficie de los tiestos, como la pintura y los residuos de cocción y hollín. Por este motivo, el número de fragmentos con restos de hollín, residuos, pintura y/o engobe debe ser considerado como un número mínimo, ya que este tipo de adherencias puderon haber sido eliminadas, en algunos casos, por factores postdepositacionales. Cabe destacar que, aunque la muestra es chica, presenta la particularidad de estar compuesta por algunos fragmentos de mayor tamaño, que permitieron realizar inferencias acerca de la forma y dimensiones de la vasija, rasgos para los que se cuenta con poca información en el NE de Patagonia y SE de la Región Pampeana.

Si bien aún no es posible determinar cuál es la causa por la que los contenedores cerámicos no alcanzaron en el área mayores frecuencias, a partir del análisis de sus características, pueden comenzar a indagarse algunas hipótesis. En tal sentido, los estudios realizados permiten proponer que: a) se confeccionaron formas globulares abiertas, de tamaño pequeño a mediano (diámetros estimados no mayores a 24 $\mathrm{cm})$, sin asas pero, en algunos casos, con orificios
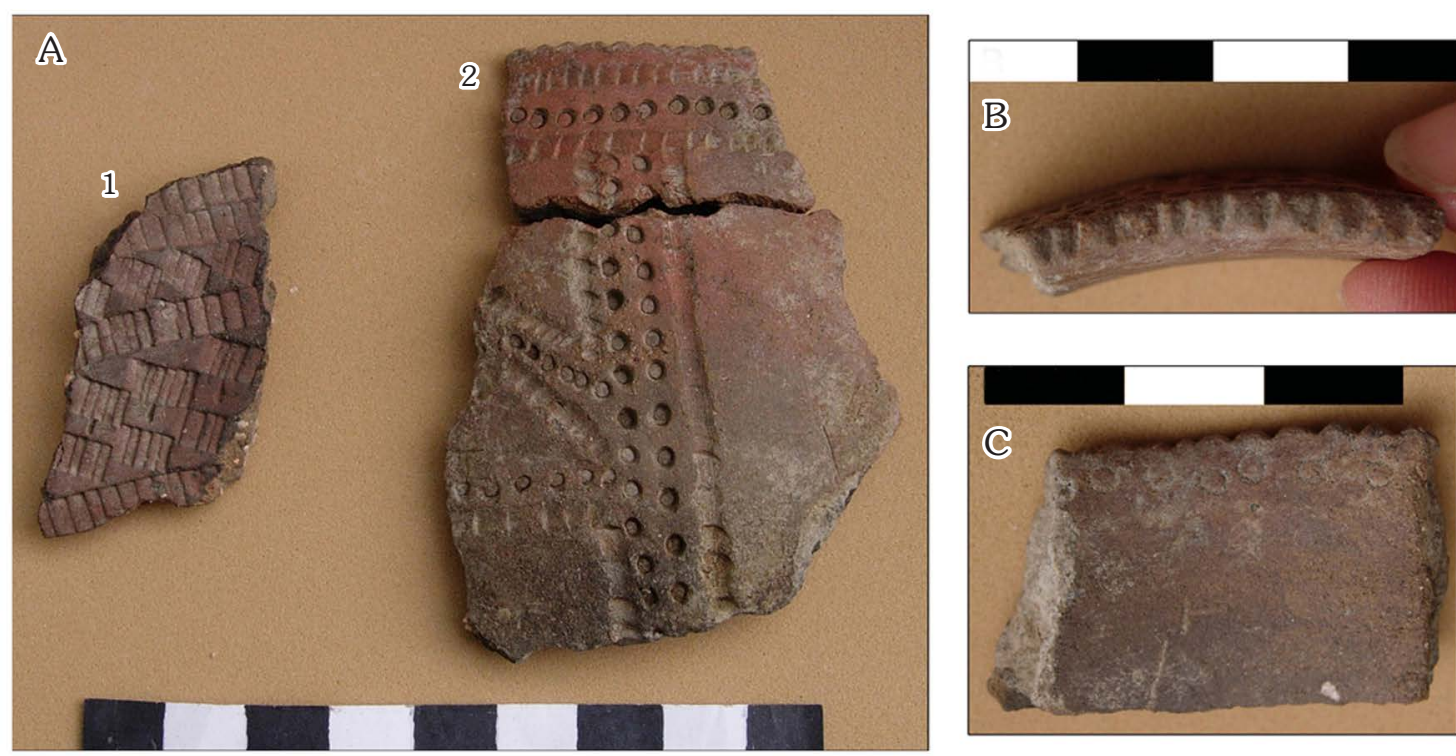

Fig. 4. Cerámica decorada recolectada por el Sr. Peluso en la laguna Chasicó.

A. decoración sobre la superficie externa; B. decoración sobre la porción de borde del fragmento 2;

C. decoración en superficie interna adyacente al borde del fragmento 2 . 
que pudieron ser utilizados para su suspensión. Estas formas y tamaños son aptas para cocinar, procesar o servir alimentos para un número reducido de personas y no estarían indicando su uso prioritario en el almacenamiento o transporte de sustancias; b) las paredes muestran espesores que varían entre $2,25 \mathrm{~mm}$ y $10,72 \mathrm{~mm}$, con el $50 \%$ de la muestra comprendido entre $4,52 \mathrm{~mm} y$ 6,25 mm (primer y tercer cuartil), encontrándose los espesores más gruesos representados en la cuenca inferior del arroyo, aunque las medianas no presentan variación entre los sectores medio $e$ inferior de la cuenca (Fig. 5). El predominio de tiestos con espesores de entre $5 \mathrm{~mm}$ y $6 \mathrm{~mm}$ en todos los sitios puede relacionarse con una moderada inversión en su manufactura (Franchetti \& Sugrañes, 2012; Simms et al. 1997), así como con su uso en procesos de cocción, ya que estos espesores son buenos conductores del calor y resistentes al shock térmico (Orton et al. 1997; Rice, 1987). El aumento en el espesor de los contenedores hacia la cuenca inferior podría responder a: a) utilización de la cerámica en actividades que requirieron de contenedores de mayor tamaño, b) menor inversión de tiempo $y$ esfuerzo en su fabricación consecuencia de una mayor movilidad residencial (Simms et al. 1997), c) menor necesidad de optimizar el aprovechamiento calórico consecuencia de la alta disponibilidad de leña en la zona (Eerkens,

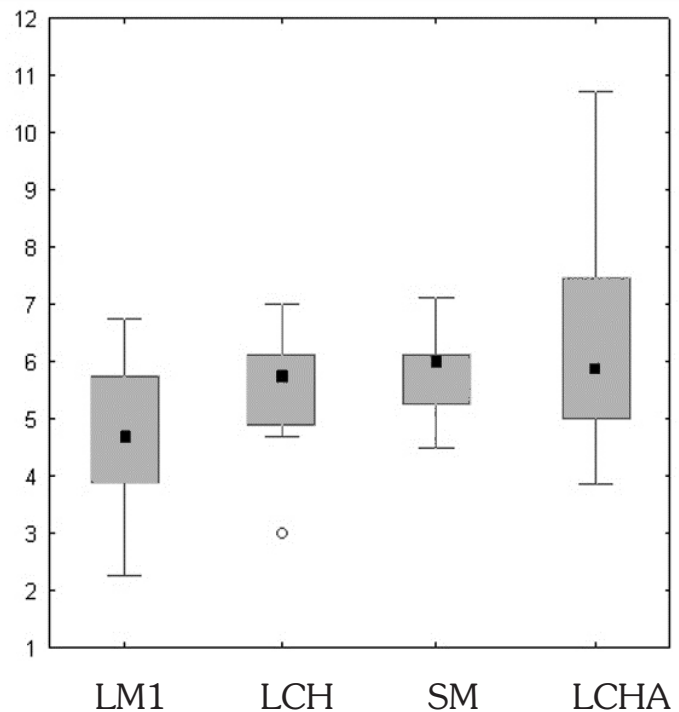

Procedencia
2003), d) problemas de muestreo, relacionados con la representación diferencial de las distintas partes de una vasija (i.e. bases que suelen ser más gruesas que los bordes).

Los colores de pasta representados indican la utilización de arcillas con porcentajes más o menos elevados de hierro, con excepción de aquellas presentes en LM1, donde la presencia de colores correspondientes al espectro 2 (rosa claro-amarillo-blanco) pueden relacionarse con el empleo de arcillas con bajo contenido de este mineral (P.C.R.G., 1995). Las pastas, en general, se encuentran de bien a moderadamente seleccionadas con antiplásticos de formas predominantemente sub-redondeadas y subangulares cuyos tamaños preponderantes no superan los $2 \mathrm{~mm}$. La forma y selección de las inclusiones parece indicar que estas no fueron incorporadas intencionalmente a las pastas empleadas en la confección de los contenedores cerámicos, sino que las arcillas pudieron haber sido limpiadas para eliminar aquellas inclusiones de mayor tamaño (Orton et al. 1997; Rice, 1987; Rye, 1994). Si bien no puede descartarse la incorporación, como antiplástico, de partículas redondeadas o subredondeadas disponibles en los sedimentos locales (e.g. arena), la única inclusión con mayor probabilidad de haber sido incorporada intencionalmente es el tiesto molido (aunque su identificación certera requiere de la realización de análisis petrográficos), presente en baja frecuencia ( 1 o 2 fragmentos por sitio) pero en todos los sitios analizados. La presencia de tiesto molido indicaría que, al menos en algunos casos, la elaboración de las vasijas se realizó en espacios donde se encontraban disponibles fragmentos cerámicos. Este tipo de inclusiones es abundante al norte de las sierras de Tandilia, pero escaso al sur de ellas, por lo que su presencia podría indicar la circulación de algunas vasijas dentro de redes amplias.
- Mediana

25\%-75\%

I Rango sin outliers

- Outliers

* Extremos
Fig. 5. Box plot representando la dispersión en espesores en las localidades arqueológicas de la cuenca del arroyo Chasicó. LM1=La Montaña 1 (cuenca superior) LCH=Laguna Los Chilenos (cuenca superior/ media) SM=San Martín (cuenca media) LCHA=Laguna Chasicó (cuenca inferior). 
El predominio de fractura irregular y pastas blandas permite inferir, si bien no de manera inequívoca, la cocción a bajas temperaturas (Orton et al. 1997; Rice, 1987). La gama de colores representada en la muestra (diferentes tonos de marrón, gris y negro) y las variaciones de color en un mismo fragmento (piezas con manchas $y$ cambios del marrón al gris en la sección), indican que el proceso de cocción se habría dado de manera incompleta en atmósfera oxidante o bien bajo condiciones de cocción variables (Orton et al. 1997; Rice, 1987). Sin embargo, no puede descartarse que los colores negros respondan a la absorción de materia orgánica por el uso de la pieza sobre el fuego (Orton et al. 1997; Skibo, 1992). En tal sentido, este tipo de uso queda evidenciado por la presencia de restos de hollin en la superficie externa.

En cuanto a la terminación de las vasijas, éstas se encuentran alisadas o toscamente alisadas, siendo escasas las superficies pulidas, lo que es coincidente con una moderada a baja inversión en su manufactura (Franchetti \& Sugrañes, 2012; Simms et al. 1997). En los pocos casos de tiestos con su superficie pulida, este tratamiento ha sido realizado de modo expeditivo, obteniéndose una superficie brillante y menos permeable, pero irregular. La proporción de tiestos decorados es baja y cuando ésta se encuentra presente se ubica en el sector adyacente al borde y consiste en incisión y/o impresión, a lo que puede agregarse pintura roja. También se encuentran fragmentos en los que se aplicó un baño o engobe, que si bien puede haber tenido una función decorativa, también cumple con la función de impermeabilizar (Orton et al. 1997). Cabe destacar que, consecuencia de procesos postdepositacionales, la presencia de pintura o engobe puede estar subrepresentada, ya que en algunos casos esta ha sido identificada sólo en la forma de pequeños restos atrapados en las líneas de incisión o poros de la cerámica.

En líneas generales, la cerámica presente en la cuenca del arroyo Chasicó muestra una baja a moderada inversión de tiempo y energía, evidenciado por un predominio de paredes con espesores entre $5 \mathrm{~mm}$ y $6 \mathrm{~mm}$, superficies alisadas o tosco-alisadas y pastas con granulometría mediana a fina, lo que a su vez es acompañado por una escasa estandarización, tanto en el tipo de tratamiento de las superficies como en el espesor de las paredes y las inclusiones representadas en la pasta. Estas características pueden relacionarse con una fabricación en contextos de movilidad residencial relativamente altos (Simms et al. 1997; Eerkens, 2003). Excepciones a esto lo constituyen los fragmentos decorados de LM1 y de la laguna Chasicó (colección Peluso). En el caso de los fragmentos de la colección Peluso, la mayor inversión de trabajo en su manufactura, está dada por la representación de complejos motivos decorativos, engobe y superficies bien alisadas y pulidas. En LM1, además de la decoración, la presencia de inclusiones con diámetro mayor a $4 \mathrm{~mm}$ en paredes que no superan los $5 \mathrm{~mm}$ de espesor, seguramente aumentó el trabajo invertido en las etapas de modelado y decoración de la vasija, por lo que la decisión de mantener este tipo de inclusiones puede estar relacionada con la búsqueda de ciertas propiedades particulares, requiriendo una mayor inversión en su fabricación. En cuanto a su posible función, la presencia de formas abiertas de pequeño a mediano tamaño, con adherencias de hollin en la superficie externa y residuos de cocción en la interna, indican el uso de los contenedores para la cocción de sustancias, probablemente alimentos, aunque no se puede descartar su uso también durante su preparación y consumo.

\section{La cuenca del arroyo Chasicó en el} contexto del sur de la Región Pampeana y el NE de Patagonia

En los apartados precedentes se desarrollaron las características de los contenedores cerámicos recuperados en la cuenca del arroyo Chasicó, ahora bien, ¿qué tendencias y/o patrones pueden observarse al ampliar la escala espacial de análisis? ¿Qué similitudes o diferencias pueden establecerse entre estos materiales y aquellos procedentes de otras áreas del NE de Patagonia y SE de la Región Pampeana? ¿Qué información puede ofrecernos analizar la distribución espacial de los fragmentos cerámicos? A los fines de poner en relación la información obtenida en la cuenca del arroyo Chasicó (i.e. mesoescala), con aquella disponible en una escala espacial más amplia, se consideró el sector centro-oriental de la República Argentina. 

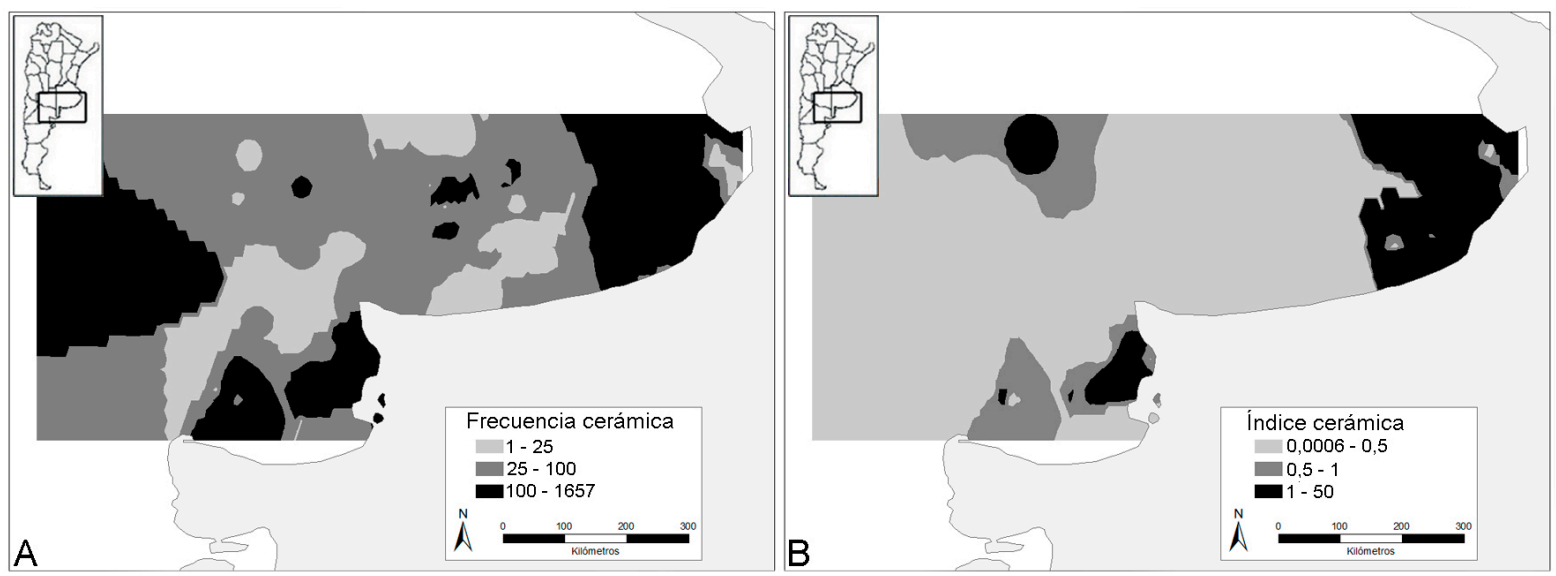

Fig. 6. Modelado de la frecuencia de aparición de material cerámico utilizando la técnica de interpolación IDW. A. frecuencias absolutas; B. frecuencias relativas.

La Fig. 6 muestra la distribución, en dicho sector, de la frecuencia de fragmentos cerámicos en términos absolutos y en relación con los artefactos líticos, utilizando la técnica de interpolación IDW. El modelo de frecuencias absolutas muestra que estas son muy variables entre sitios o localidades relativamente cercanas, pero muestran ciertas tendencias cuando se relativizan en relación con los artefactos líticos. Analizando comparativamente los modelos, puede observarse que únicamente la cuenca inferior de los ríos Negro y Colorado y el área de la Depresión del río Salado se destacan en ambos modelos como sectores con mayor frecuencia cerámica. El pico localizado en el sector oeste (cuenca media de los ríos Negro y Colorado) en cambio, se relativiza al comparar las frecuencias cerámicas con las líticas, al igual que algunos picos representados en el área Interserrana. Por otra parte, hacia el noroeste del área considerada surge un pico de frecuencias que, si bien no estaba presente en el modelo de frecuencias absolutas, se hace evidente al comparar estas frecuencias con las líticas. El mayor número de picos en el modelo de frecuencias absolutas (y que no tienen su correlato en el modelo de frecuencias relativas) puede deberse a la existencia de zonas de mayor ocupación (ya sea por permanencia prolongada, mayor redundancia en la ocupación de sectores particulares o mayor concentración de población,

2 La historia de las investigaciones en la Región Pampeana y el NE de Patagonia a tenido un muy disímil desarrollo, con sectores como el área Interserrana y las sierras de Tandilia donde se realizan investigaciones con continuidad desde al menos en momentos particulares) o bien a áreas donde la intensidad en las investigaciones ha sido mayor $^{2}$. Las zonas de mayor frecuencia, tanto absoluta como relativa, tienden a encontrarse en la Depresión del Río Salado, sector SE de las sierras de Tandilia y en la desembocadura del río Colorado. Esta distribución se ajusta, en términos generales, a la variación espacial en la disponibilidad de materiales leñosos y, en menor medida, a la disponibilidad de recursos acuáticos (principalmente peces de agua dulce). En efecto, las áreas que registran las más altas frecuencias, particularmente en el caso de las frecuencias relativas, se encuentran comprendidas dentro de las zonas correspondientes a la distribución subactual de diferentes distritos de la Provincia Fitogeográfica del Espinal (Burkart et al. 1999; Torres Robles, 2009), así como de sectores de Tandilia con abundancia de curro (Cabrera \& Zardini, 1978; Cicchino \& Farina, 2007). Además, algunas de las áreas con mayores frecuencias cerámicas son concordantes también con aquellos sectores para los que, durante el Holoceno tardío, ha sido reportado el consumo de peces, marinos y/o fluviales (González, 2005; González et al. 2012; Martínez et al. 2005; Stoessel, 2012).

Por otra parte, el análisis sobre las características de espesor, porcentaje de inclusiones y textura de la cerámica de las áreas de Tandilia, Interserrana, Ventania y Sur,

principios del siglo XX y otras donde las investigaciones se inician más tardiamente o bien presentan discontinuidades en su desarrollo. 


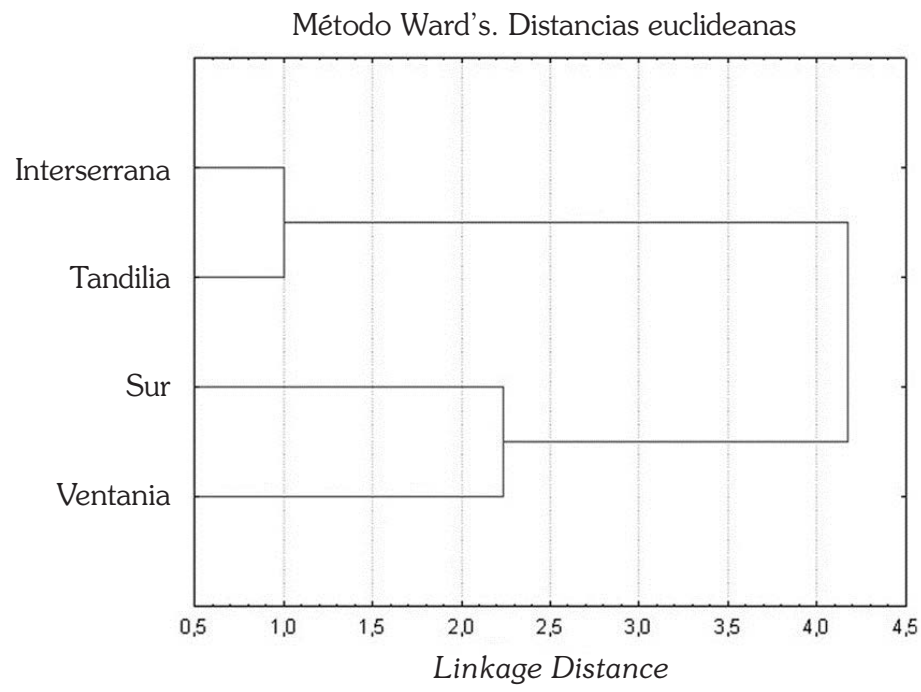

Fig. 7. Análisis cluster entre muestras procedentes de las áreas Interserrana, Tandilia, Sur y Ventania. En la tabla se muestran los valores considerados para generarlo. Textura: 1- fina, 2- media, 3- gruesa; \% inclusiones: 1- 15\%-20\%, 2- 20\%-25\%, 3- 25\%$30 \%$, 4- 30\%-35\%, 5- 35-40\%, 6- 40\%-45\%.

reflejan una mayor semejanza entre las muestras de las áreas Interserrana y Tandilia por un lado y Sur y Ventania por otro. Es decir que, tecnológicamente $y$, en función de las variables consideradas, las cerámicas procedente de las áreas Ventania y Sur tienden a presentar mayor similitud entre sí y se diferencian de aquellas recuperadas en el sistema serrano de Tandilia y en el área Interserrana (Fig. 7), esta tendencia deberá continuar indagándose por medio de la incorporación de otras variables y nuevas muestras cerámicas.

\section{DISCUSIÓN Y CONCLUSIONES}

El análisis de la información considerando diferentes escalas espaciales (i.e. meso y macro escala) tiene la ventaja de poner en evidencia tendencias y patrones que, de otra manera, pueden no hacerse evidentes. En una escala espacial amplia (i.e. macroescala) la concordancia entre áreas con mayor frecuencia de materiales cerámicos y aquellas con mayor densidad de especies arbóreas factibles de ser utilizadas como combustible muestra que la disponibilidad de leña pudo ser una limitante en la producción cerámica en muchas zonas de la Región Pampeana. Las mayores frecuencias cerámicas también son coincidentes en algunas áreas con la disponibilidad de otros recursos, como por ejemplo peces, los que -además de posibilitar una menor movilidad- dada su localización y predictibilidad, pueden requerir de este tipo de contenedores para su procesamiento $\mathrm{y} / \mathrm{o}$ almacenamiento. En cuanto a las pastas, la mayor similitud entre aquéllas procedentes de las áreas Ventania y Sur con respecto a las procedentes de Tandilia e Interserrana, pareciera dar sustento a la hipótesis de una manufactura local, supeditada a las necesidades del grupo. Sin embargo, deberán continuar explorándose diferentes líneas de evidencia, como la realización de estudios petrográficos y análisis de potenciales fuentes de arcilla en Ventania y la llanura adyacente al sudoeste de dicho sistema serrano.

Tanto las formas representadas como los diseños decorativos muestran similitudes con aquellos descriptos para otras áreas de la Región Pampeana y el NE de Patagonia. Entre los motivos similares se encuentran el surco rítmico formando rectángulos o "banderitas" y, con menor frecuencia, las impresiones circulares y la decoración del labio mediante líneas incisas transversales al mismo (Aldazabal, 2008; Di Prado, 2013, 2015; González \& Frère, 2010). Los motivos decorativos registrados en el sitio La Montaña (triángulo enmarcado y líneas paralelas y entrecruzadas) muestran semejanzas con aquellos registrados por Outes (1908) en la cerámica de Bahía San Blas y con motivos presentes en una placa grabada recolectada por J. M. Torres en la misma zona (Fig. 8). Las líneas entrecruzadas y los triángulos rellenos con ellas (aunque estos últimos sin el marco) también se observan en la cerámica 
del curso medio del río Negro (Di Prado, 2013), en placas y hachas grabadas de la zona de San Blas y en la decoración de huevos de Rheidae del NE de Patagonia (Carden \& Martínez, 2014; Fiore \& Borella, 2010) y de las lagunas Encadenadas del Oeste de la Provincia de Buenos Aires (Panizza, 2013). La presencia de motivos que muestran, si bien con variaciones particulares, reglas de composición compartidas y elementos comunes con aquellos descriptos para el SE de la Región Pampeana y NE de Patagonia, así como con algunos motivos presentes en otros soportes muebles (Carden \& Martínez, 2014; Fiore \& Borella, 2010; Oliva, 2006, 2017; Panizza, 2013), sustenta la idea de la existencia de redes sociales de intercambio de bienes e información, dentro de los cuales pudieron circular ciertos elementos (entre ellos algunos de los contenedores cerámicos).

En la cuenca del arroyo Chasicó, la baja representación de la tecnología cerámica puede estar respondiendo tanto a factores ambientales y/o sociales que limitaron o desmotivaron su uso como a procesos post-depositacionales que afectaron a su conservación. El hecho de que las muestras cerámicas analizadas procedan de contextos y ambientes diferentes (estratigrafía, superficie, ambientes lagunares, ambientes fluviales) y hayan sido recolectados tanto por investigadores como por coleccionistas locales (quienes tienen mayores probabilidades de hallar registros poco frecuentes), vuelve menos probable la hipótesis de la acción de agentes postdepositacionales como principal causa de su baja frecuencia. En relación con los factores ambientales, la disponibilidad de recursos naturales no parece haber sido un determinante en la cuenca del arroyo Chasicó, ya que en ella se encuentran abundantes fuentes de arcillas (que son utilizadas actualmente por ceramistas locales para la fabricación de artesanías), agua y especies leñosas, como Prosopis sp. y Condalia sp., que dan brasa buena y durable (Marconetto, 1999), pudiendo ser usadas para la cocción de los contenedores cerámicos.

La poca utilización de cerámica podría responder, al menos en la cuenca del arroyo Chasicó, a un contexto social que limitó su incorporación. En este sentido, la baja frecuencia
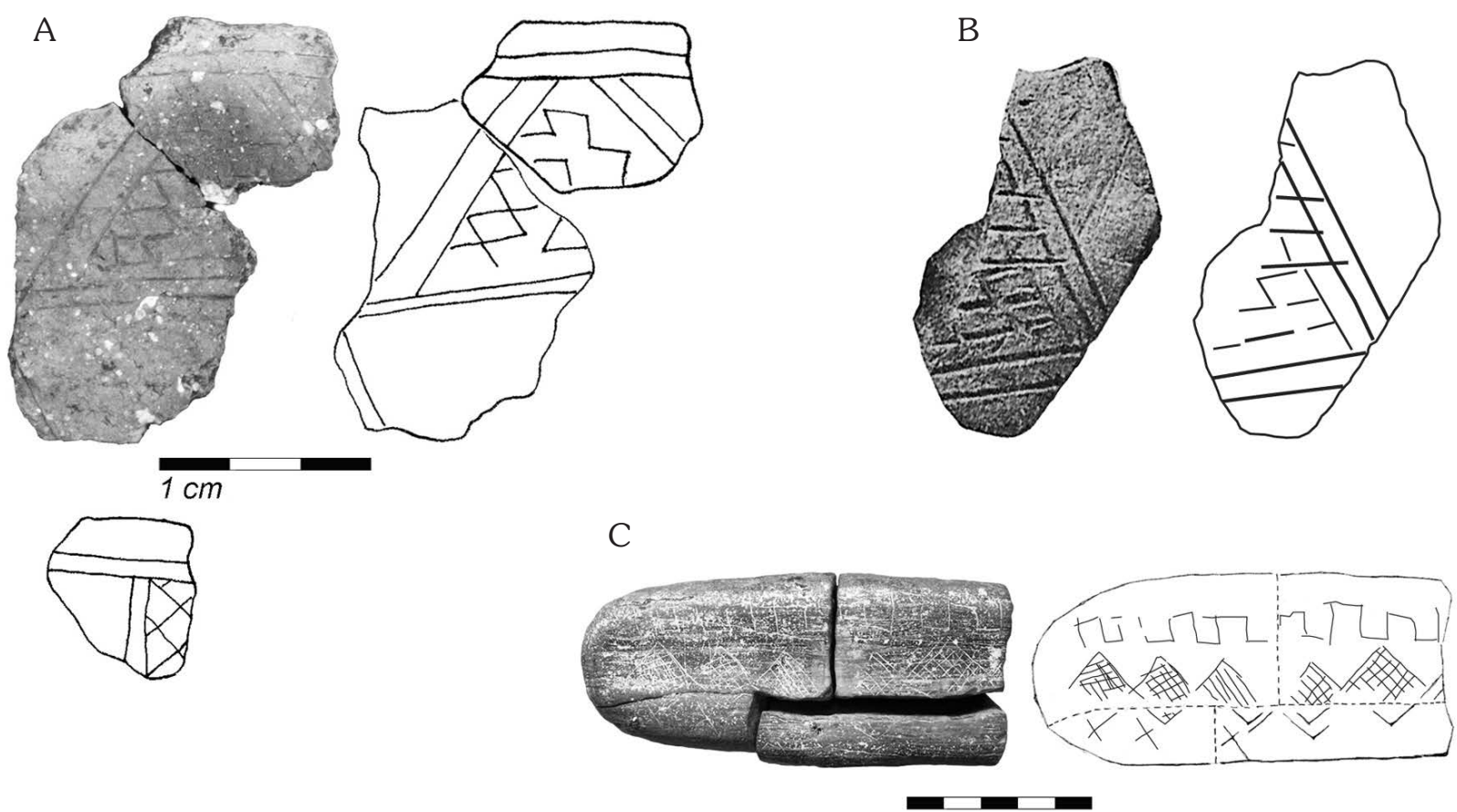

Fig. 8. Motivos decorativos registrados en A- cerámica de La Montaña sitio 1;

B. Cerámica de Bahía San Blas (Outes, 1908); C- Placa grabada de la colección Torres (MLP). 
de los materiales cerámicos puede relacionarse con una movilidad residencial relativamente alta, dado que el volumen y peso, junto a la fragilidad de estos contenedores, pueden restringir su uso en este tipo de sociedades. Por otra parte, las altas frecuencias de contenedores cerámicos suelen asociarse a la incorporación de nuevas técnicas en el procesamiento de los alimentos (i.e. hervido), producto de un proceso de intensificación en la utilización de los recursos. Si bien para otras áreas, como la desembocadura de los ríos Negro y Colorado, se ha propuesto que durante el Holoceno tardío se produjo un aumento en la intensidad de procesamiento de los recursos faunísticos y una mayor amplitud de la dieta (Barrientos, 2001; Martínez, 2002, 2010), en la cuenca del arroyo Chasicó en particular, y en las sierras de Ventania y la llanura al sudoeste de ellas en general, no se han registrado indicadores que permitan suponer la existencia de un proceso de intensificación, al menos no en la escala propuesta para otras áreas (e.g. no se registran cambios importantes en el tipo y modo de utilización de la fauna, los artefactos de molienda continúan siendo mayormente de pequeño tamaño y con poca inversión en su manufactura) (Catella, 2014). En este contexto, muchas de las funciones de los contenedores cerámicos, pudieron llevarse a cabo con otro tipo de recipientes más livianos y menos frágiles (e.g. cueros, contenedores vegetales), por lo que su uso se habría restringido a llevar a cabo actividades específicas desarrolladas en ciertos lugares del paisaje (e.g. cocción y/o procesamiento de recursos particulares).

La información actualmente disponible sobre los materiales cerámicos ha permitido modelar tendencias que plantean nuevas preguntas y vías de análisis en relación con el rol jugado por esta tecnología en las sociedades cazadoras-recolectoras del SE de la Región Pampeana y NE de Patagonia, que deberán ser consideradas con mayor detalle en el futuro. En tal sentido, deberá avanzarse con los análisis sobre la composición de las pastas, su procedencia y la función que los contenedores cerámicos tuvieron en el área de estudio.

\section{AGRADECIMIENTOS}

A Gustavo Barrientos, Fernando Oliva, María Cecilia Panizza y Maricel Pérez, quienes realizaron numerosos comentarios que enriquecieron este trabajo. A la Prof. Nora Cinquini y al Sr. Peluso por facilitarme el acceso a los materiales cerámicos de colecciones. A Rodolfo Raffino, por autorizar el análisis las colecciones arqueológicas depositadas en el Museo de La Plata y a Gabriel Alarcón y Jorge Kraideberg por su bueno predisposición y ayuda durante la realización de estas tareas. A Iren Morelli por su ayuda con los dibujos. Los trabajos de campo y análisis de los materiales se realizaron en el marco de los proyectos N629 y N740 (FCNyM, Universidad Nacional La Plata), 1 Hum185 (FHumyAr, Universidad Nacional Rosario), y de un Subsidio Jóvenes Investigadores otorgado por la Universidad Nacional de La Plata.

\section{BIBLIOGRAFÍA}

Aldazabal, V. (2008). Entre líneas y puntos. Interpretando aspectos del diseño de la cerámica del sector centrooriental de la Pampa Deprimida, Provincia de Buenos Aires, Argentina. Relaciones de la Sociedad Argentina de Antropología, 33, 61-84.

Aldazabal, V., Eugenio, F., \& Macchi, D. (2015). Circulación de motivos decorativos en la cerámica de los cazadores-recolectores de la Pampa Deprimida, Provincia de Buenos Aires, Argentina. Relaciones de la Sociedad Argentina de Antropología, 40(1), 183-207.

Andrews, L., Higgins, A., Waring Andrews, M., \& Lalor, J. G. (2012). Classic grounded theory to analyse secondary data: reality and reflections. Grounded Theory Review, An International Journal, 11(1) Recuperado en: http://groundedtheoryreview. com/2012/06/01/classic-grounded-theory-toanalyse-secondary-data-reality-and-reflections/

Arnold, D. E. (1985). Ceramic Theory and Cultural Process. Cambridge University Press, Cambridge.

Barrientos, G. (1997). Nutrición y dieta de las poblaciones aborígenes prehispánicas del sudeste de la región pampeana. Tesis inédita de doctorado. Facultad de Ciencias Naturales y Museo, UNLP, La Plata.

Barrientos, G. (2001). Una aproximación bioarqueológica al estudio del poblamiento prehispánico tardío del Sudeste de la Región Pampeana. Intersecciones en 
Antropología, 2, 3-18.

Barrientos, G., Oliva, F., \& del Papa, M. (2002). Historia predepositacional y tafonómica del entierro secundario del sitio Laguna Los Chilenos 1 (Provincia de Buenos Aires). Relaciones de la Sociedad Argentina de Antropología, 27, 303-326.

Barrientos, G., Catella L., \& Oliva F. (2015). The spatial structure of lithic landscapes: the late Holocene record of east-central Argentina as a case study. Journal of Archaeological Method and Theory, 22, 1151-1192.

Berón, M. (2004). Dinámica poblacional y estrategias de subsistencia de poblaciones prehispánicas de la cuenca Atuel-Salado-Chadileuvú-Curacó, Provincia de La Pampa. Tesis inédita de doctorado. Universidad de Buenos Aires.

Berón, M., \& Politis, G. (1997). Arqueología Pampeana en la década de los '90. Estado de las investigaciones y perspectivas. En M. Berón, \& G. Politis (Comp.), Arqueología Pampeana en la Década de los ‘90 (pp. 7-32). Mendoza: Museo de Historia Natural de San Rafael. INCUAPA, Facultad de Ciencias Sociales, UNCPBA.

Bonomo, M. (2005). Costeando las llanuras. Arqueología del litoral marítimo pampeano. Buenos Aires: Sociedad Argentina de Antropología.

Bonorino, A., Ruggiero, E., \& Mariño, E. (1989). Caracterización hidrológica de la cuenca del arroyo Chasicó. Programa Prioritario de Asesoramiento a Municipalidades. CIC. La Plata.

Borges Vaz, E., Martínez, G., \& Madrid, P. (2016). Análisis tecnomorfológicos y tendencias cronológicas del conjunto cerámico del sitio Loma Ruíz 1 (transición pampeano-patagónica oriental). Aportes para Pampa y Norpatagonia. Intersecciones en Antropología, 17, 269-280.

Braun, D. (1983). Pots as tools. En J. A. Moore \& A. S. Keene (Eds.), Archaeological hammers and theories (pp. 107-134). Elsevier Inc, Academic Press New York.

Bright, I. R. \& Ugan, A. (1999). Ceramics and Mobility: Assessing the Role of Foraging Behavior and its Implications for Culture-History. Utah Archaeology, 12, 17-29.

Burkart, R., Bárbaro, N., Sánchez, R. O., \& Gómez, D. A. (1999). Eco-regiones de la Argentina. Administración de Parques Nacionales. Buenos Aires. Argentina.

Burrough, P. A. \& McDonnell, R. A. (1998). Principles of
Geographical Information Systems. Oxford: Oxford University Press.

Cabrera, A. L. (1971). Fitogeografía de la República Argentina. Boletín de la Sociedad Argentina de Botánica, 14 (1-2), 1-42.

Cabrera, A. L., \& Zardini, E. M. (1978). Manual de la flora de los alrededores de Buenos Aires. Buenos Aires, Editorial Acme.

Carden, N., \& Martínez, G. (2014). Diseños fragmentados. Circulación social de imágenes sobre huevos de Rheidae en Pampa y Norpatagonia. Boletín del Museo Chileno de Arte Precolombino, 19(2), 5575.

Cassiodoro, G., \& Tessone, A. (2014). Análisis radiocarbónico y de isótopos estables en residuos cerámicos del centro-oeste de Santa Cruz (Patagonia). Relaciones de la Sociedad Argentina de Antropología, 34(1), 293-299.

Catella, L. (2004). Análisis tecnológico del material cerámico del Sistema Serrano de Ventania y llanura adyacente (Provincia de Buenos Aires). Miradas. Trabajos de las V Jornadas de Jóvenes Investigadores en Ciencias Antropológicas (pp. 170-183). Buenos Aires: Instituto Nacional de Antropología y Pensamiento Latinoamericano.

Catella, L. (2014). Movilidad y utilización del ambiente en poblaciones cazadoras-recolectoras del sur de la Región Pampeana: la cuenca del arroyo Chasicó como caso de estudio. Tesis inédita de doctorado. Facultad de Ciencias Naturales y Museo, Universidad Nacional de La Plata.

Catella, L., \& Saghessi M. (2007). Estudio del material cerámico del área de Las Encadenadas, Partido de Guaminí (Provincia de Buenos Aires). En F. Oliva, N. de Grandis, \& J. Rodríguez (Comp.), Arqueología Argentina en los Inicios de un Nuevo Siglo. Publicación del XIV Congreso Nacional de Arqueología Argentina (pp. 557-566). Rosario: Universidad Nacional de Rosario.

Church, R. R., \& Lyman, R. L. (2003). Small fragments make small differences in efficiency when rendering grease from fractured artiodactyla bones by boiling. Journal of Archaeological Science, 30, 1077 1084. doi:10.1016/S0305-4403(03)00010-4

Cicchino, A. C., \& Farina, J. L. (2007). Riqueza, dominancia y fenología primaveral, estival y otoñal de los carábidos edáficos (insecta, coleoptera) de los currales serranos y periserranos de las sierras de Mar del Plata, provincia de Buenos Aires, Argentina. VI 
Reunión Nacional Científico Técnica de Biología del Suelo. VI Encuentro sobre Fijación Biológica de Nitrógeno (pp. 1-16) Río Cuarto, Córdoba, Recuperado en: http://naturalis.fcnym.unlp.edu.ar/ repositorio/_documentos/sipcyt/bfa002902.pdf

Cremonte, M. B. (1983-1985). Alcances y objetivos de los estudios tecnológicos en la cerámica arqueológica. Anales de Arqueología y Etnología, 38/40, 179217. Universidad Nacional de Cuyo.

Crivelli Montero, E. A (1993-1994). Estructuras en sitios arqueológicos de la pampa interserrana bonaerense. Casos e implicancias. Relaciones de la Sociedad Argentina de Antropología, 19, 257-283.

Dean, P. A., \& Heath, K. (1990). Form and Function: Understanding Gray Pottery in the Northeast Great Basin. En J. M. Mack (Ed.), Hunter-Gatherer Pottery from the Far West (pp. 19-28). Nevada State Museum Anthropological Papers No23. Carson City.

Devine, P. (2003). Secondary data analysis. En R. L. Miller \& J. D. Brewer (Eds.), The A-Z of Social Research (pp. 285-288). Sage.

Di Prado, V. (2013). Del interior a la superficie. Análisis de las pastas y las representaciones decorativas de la alfarería de Loma de los Muertos (Este de Nordpatagnia). Magallania, 41(2), 197-214.

Di Prado, V. (2015). Estudio comparativo de las prácticas de elaboración y uso de la alfarería prehispánica del centro-este de Argentina desde una perspectiva macrorregional. Tesis inédita de doctorado. Facultad de Ciencias Naturales y Museo, Universidad Nacional de La Plata.

Di Prado, V. (2016). Prácticas de elaboración y uso de la alfarería prehispánica del este de Norpatagonia. Relaciones de la Sociedad Argentina de Antropología, 41(2), 397-419.

Eerkens, I. W. (2003). Residential Mobility and Pottery Use in the Western Great Basin. Current Anthropology, 44(5), 728-738.

Eerkens, I. W. (2004). Privatization, small-seed intensification, and the origins of pottery in the western Great Basin. American Antiquity, 69(4), 653-670.

Eerkens, I. W. (2008). Nomadic potters: relationships between ceramic technologies and mobility strategies. En $\mathrm{H}$. Barnard \& W. Wendrich (Eds.), The Archaeology of Mobility: Old World and New World Nomadism (pp. 307-326). Los Angeles: Cotsen Institute of Archaeology.

Eerkens, I. W., Neff, H., \& Glascock, M. (2002). Ceramic production among small-scale and mobile hunters and gatherers: A case study from the Southwestern Great Basin. Journal of Anthropological Archaeology, 2, 200-229.

Eugenio, E., \& Aldazabal, V. (2004). Los cazadores recolectores del litoral marítimo del área de Bahía de San Blas, Provincia de Buenos Aires. En M. T. Civalero, P. M. Fernández, \& A. G. Guráieb (Comp.), Contra viento y marea. Arqueología de Patagonia (pp. 687-700). Buenos Aires: Instituto Nacional de Antropología y Pensamiento latinoamericano, Sociedad Argentina de Antropología.

Eugenio, E., \& Aldazabal, V. (2013). Características petrográficas de la cerámica de litoral de la Bahía San Blas. En A. Zangrando, R. Barberena, A. Gil, G. Neme, M. Giardina, L. Luna, C. Otaola, S. Paulides, L. Salgán, \& A. Tivoli (Comp.), Tendencias teóricometodológicas y casos de estudio en la arqueología de la Patagonia (pp. 81-86). Mendoza: Museo de Historia Natural de San Rafael.

Eugenio, E., Aldazabal, V., Crivelli, E., \& Silveira, M. (19871988). La cerámica del sitio Fortín Necochea; recolección de superficie. Paleoetnologica, 4, 97103.

Fielding, N. (2004). Getting the most from archived qualitative data: epistemological, practical and professional obstacles. International. Journal of Social Research Methodology, 7 (1), 97-104.

Fiore, D., \& Borella, F. (2010). Geometrías delicadas. Diseños grabados en cáscaras de huevo de Rheidae recuperados en la costa norte del Golfo San Matías, Río Negro. Intersecciones en Antropología, 11(2), 277-293.

Franchetti, F., \& Sugrañes, N. (2012). Ceramic technology, environment \& residential mobility in small scale groups: preliminary trends from north Patagonia, Argentina. Before Farming, 3, article 2. doi:http:// dx.doi.org/10.3828/bfarm.2012.3.3.

Frère, M. M. (2015). Tecnología Cerámica de los CazadoresRecolectores-Pescadores de la Microrregión del Río Salado, Provincia de Buenos Aires. Tesis inédita de doctorado. Facultad de Filosofía y Letras, Universidad de Buenos Aires, Buenos Aires.

González, M. I. (2005). Arqueología de alfareros, cazadores y pescadores pampeanos. Sociedad Argentina de Antropología.

González, M. I., \& Frère, M. M. (2010). Diseños prehispánicos de la alfarería pampeana. Editorial de la Facultad de Filosofía y Letras (UBA), Buenos Aires. 
González, M. I., Frère, M. M., \& Fiore, D. (2007). Redes de Interacción en la Cuenca Inferior y Media del Salado. En C. Bayón, A. Pupio, M. I. González, N. Flegenheimer, \& M. M. Frère (Eds.), Arqueología en las pampas $\mathrm{N}^{\circ} 1$ (pp. 365-385). Buenos Aires: Sociedad Argentina de Antropología.

González, M. I., Frère, M. M., \& Frontini, R. (2012). Formas de ollas de cerámica pampeana y consumo de alimentos. En M. P. Babot, M. Marschoff \& F. Pazzarelli (Eds), Las manos en la masa. Arqueologías, Antropologías e Historias de la Alimentación en Suramérica (pp. 405-424). Córdoba: Universidad Nacional de Córdoba.

González de Bonaveri, M. I., Frère, M. M., \& Solá, P. (2000). Petrografía de cerámicas arqueológicas de la cuenca del río Salado, provincia de Buenos Aires. Relaciones de la Sociedad Argentina de Antropología, 25, 207-226.

Hayden, B. (1990). Nimrods, Piscators, Pluckers, and Planters: The emergence of food production. Journal of Anthropological Archaeology, 9, 31-69.

Hayden, B. (1995). The emergence of prestige technologies and pottery. En W. K. Barnett \& J. W. Hoopes (Eds.), The Emergence of Pottery: Technology and Innovation in Ancient Societies (pp. 257-265). Smithsonian Institution, Washington D.C.

Hill, D. V. (2006). Theoretical and methodological approaches to the study of the ceramics of protohistoric semisedentary hunter-gatherers. Trabajo presentado en Transitions from Prehistory into History in the Mogollon Area: An Emphasis on Mobile Groups, the 2006 Mogollon Conference, Tucson, Arizona. Recuperado en https://www.academia. edu/214159/Theoretical_and_Methodological_ Approaches_to_the_Study_of_the_Ceramics_of Protohistoric_Semi-Sedentary_Hunter-Gatherers.

Hoopes, J. W. (1995). Interaction in hunting and gathering societies as a context for the emergence of pottery in the Central American Isthmus. En W. K. Barnett \& J. W. Hoopes (Eds.), The Emergence of Pottery: Technology and Innovation in Ancient Societies (pp. 185-198). Washington D.C.: Smithsonian Institution.

Linton, R. (1944). North American Cooking Pots. American Anthropologist, 9(4), 369-380.

Madrid, P. (1997). Análisis petrológicos y alfarería pampeana. En M. Berón \& G. Politis (Comp.), Arqueología Pampeana en la década de los 90 (pp. 61-70). Mendoza: Museo de Historia Natural de
San Rafael, XI Congreso Nacional de Arqueología Argentina, INCUAPA - Facultad de Ciencias Sociales (UNCPBA).

Marconetto, B. (1999). Las leñas del jagüar. En C. Aschero, M. Korstanje, \& P. Vuoto (Eds.), En los Tres Reinos: Prácticas de Recolección en el Cono Sur (pp. 179. 186). Tucumán: Instituto de Arqueología y Museo, Facultad de Ciencias Naturales e Instituto Miguel Lillo, Universidad Nacional de Tucumán.

Martínez, G. (2002). Organización y cambio en las estrategias tecnológicas: un caso arqueológico e implicaciones comportamentales para la evolución de las sociedades cazadoras-recolectoras pampeanas. En G. Martínez \& J. Lanata (Eds.), Perspectivas Integradoras entre Arqueología y Evolución. Teoría, Método y Casos de Aplicación (pp. 121-156). Olavarría, Buenos Aires.

Martínez, G. (2010). Arqueología de los grupos cazadoresrecolectores del curso inferior del río Colorado (partidos bonaerenses de Villarino y de Patagones). En R. Masera (Comp.), Los ríos mesetarios norpatagónicos. Aguas generosas del Ande al Atlántico (pp. 167-194). Río Negro: Gobierno de Río Negro. Ministerio de Producción.

Martínez, G., Zangrando, F., \& Stoessel, L. (2005). Sitio el Tigre (Pdo. De Patagones; Pcia de Buenos Aires, Argentina): evidencias sobre la explotación de peces en el curso inferior del río Colorado e implicaciones para los sistemas de subsistencia. Magallania, 33(2), 127-142.

Matthew, J. A., Woods, A. J., \& Oliver, C. (1991). Point before eyes. En A. Middleton, \& I. Freestone (Eds.), Recent Developments in Ceramic Petrology. Occasional Paper N81. British Museum.

Mazzanti, D., \& Porto López J. (2007). Caracterización petrográfica y estructural de cerámicas arqueológicas de las Sierra de Tandilia. En M. Cremonte \& N. Ratto (Eds.), Cerámicas Arqueológicas. Perspectivas arqueométricas para su análisis e interpretación (pp. 97-122). Jujuy: Universidad Nacional de Jujuy.

Oliva, F. (2000). Análisis de las localizaciones de los sitios con representaciones rupestres en el sistema de Ventania, Provincia de Buenos Aires. En M. M. Podestá \& M. de Hoyos (Eds.), Arte en las Rocas (pp. 143-158). Buenos Aires: Sociedad Argentina de Antropología.

Oliva, F. (2006). Uso y contexto de producción de elementos "simbólicos" del sur y oeste de la provincia de Buenos Aires, República Argentina (Área Ecotonal Húmeda Seca Pampeana). Revista de la Escuela de 
Antropología, 12, 101-116.

Oliva, F. (2017). Investigaciones arqueológicas en el sector centro-occidental de la Sierra de la Ventana y la llanura adyacente. Tesis inédita de doctorado en preparación. Facultad de Ciencias Naturales y Museo (UNLP). MS.

Oliva, F., Gil, A., \& Roa, M. (1991). Recientes Investigaciones en el Sitio San Martín 1 (BU/PU/S). Partido de Puan, Pcia de Bs As. Shincal. X Congreso Nacional de Arqueología Argentina, 3(3), 135-139.

Oliva, F., Levin, E., Moirano, J., \& Avila, D. (2000). Investigaciones arqueológicas de momentos tardíos en el Abra de Saavedra, Provincia de Buenos Aires. Trabajo presentado al II Congreso de Arqueología de la Región Pampeana Argentina. MS.

Oliva, F., \& Panizza, M. C. (2014). Estética de la producción cerámica del Área Ecotonal Húmedo Seca Pampeana (Provincia de Buenos Aires). Trabajo presentado al II Congreso Internacional de Arqueología de la Cuenca del Plata, San José de Mayo, Uruguay 7 al 11 de abril de 2014.

Orton, C., Tyers, P., \& Vince, A. (1997). La cerámica en arqueología. Barcelona, Ed. Crítica.

Outes, F. (1908). Arqueología de San Blas (provincia de Buenos Aires). Anales del Museo Nacional de Buenos Aires, 16, 249-273.

Ozán, I. (2010). Rompecabezas incompletos. Una evaluación desde los procesos de formación. En M. Berón, L. Luna, M. Bonomo, C. Montalvo, C. Aranda, \& M. Carrera Aizpitarte (Eds.), Mamül Mapu: pasado y presente desde la arqueología pampeana Vol 2 (pp. 387-399). Ayacucho, Buenos Aires: Editorial libros del Espinillo.

Panizza, M. C. (2013). Estética abstracta geométrica de los cazadores-recolectores del área de Ventania (Provincia de Buenos Aires, República Argentina). Boletín del Museo Chileno de Arte Precolombino, 18 (2), 49-61.

P.C.R.G. Prehistoric Ceramics Research Group. (1995). The study of later prehistoric pottery. General policies and guidelines for analysis and publication. England, The Prehistoric Ceramics Research Group. Occasional Papers $\mathrm{N}^{\circ} 1$ and 2.

Politis, G., \& Madrid, P. (2001). Arqueología pampeana: estado actual y perspectivas. En E. Berberián \& A. Nielsen (Eds.), Historia Argentina Prehispánica vol 2 (pp. 737-814). Editorial Brujas. Córdoba.

Politis, G., Martínez, G., \& Bonomo, M. (2001). Alfarería temprana en sitios de cazadores recolectores de la Región Pampeana (Argentina). Latin American
Antiquity, 12 (2), 167-181.

Prates, L. (2004). Arqueología de la cuenca media del Río Negro (Provincia de Río Negro). Una primera aproximación. Intersecciones en Antropología, 5, 55-69.

Prates, L., Di Prado, V., Mange, E., \& Serna, A. (2010). Sitio Loma de los Muertos. Múltiples ocupaciones sobre un médano del este de Nordpatagonia (Argentina). Magallania, 38(1), 165-181.

Primera Convención Nacional de Antropología. (1966). Cerámica. Publicaciones Nueva Serie, 1(26), $27-$ 55. Instituto de Antropología, Facultad de Filosofía y Humanidades, Universidad Nacional de Córdoba.

Quattrocchio, M. E., Borromei, A., Deschamps, C., Grill, S., \& Zavala, C. (2008). Landscape evolution and the climate changes in the Late PleistoceneHolocene, southern Pampa (Argentina): Evidence from palynology, mammals and sedimentology. Quaternary International, 181, 123-138.

Reid, K. C. (1989). A Material Science Perspective on Hunter-Gatherer Pottery. En G. Bronitsky (Ed.), Pottery Technology: Ideas and Approaches (pp. 167-180). Westview Press, Boulder.

Rice, P. (1987). Pottery Analysis. A Sourcebook. University of Chicago Press. Chicago.

Rye, O. (1994). Pottery Technology. Manuals on Archaeology 4. Taraxacum. Washington.

Shepard, A. O. (1956). Ceramics for the archaeologist. Publication 609. Carnegie Institution of Washington, Washington D.C.

Simms, R., Bright, J., \& Ugan, A. (1997). Plain-ware ceramics and residential mobility: a case study from the Great Basin. Journal of Archaeological Science, 24, 779-792.

Skibo, J. M. (1987). Fluvial sherd abrasion and the interpretation of surface remains on Southwestern. North American Archaeologist, 8, 125-142.

Skibo, J. M. (1992). Pottery function. A use alteration perspective. Plenum Press, Nueva York y Londres.

Skibo, J., Schiffer, M., \& Reid, K. (1989). Organic-tempered pottery: an experimental study. American Antiquity, 54(1), 122-146.

Stoessel, L. (2012). Consumo de peces en el área ecotonal árida-semiárida del curso inferior del río Colorado (Provincia de Buenos Aires) durante el Holoceno tardío. Relaciones de la Sociedad Argentina de Antropología, 37, 159-182.

Stoessel, L., Martínez G., \& Constenla D. (2015). Análisis preliminar de ácidos grasos recuperados de cerámicas arqueológicas 
del curso inferior del río Colorado (norpatagonia oriental): aportes para la subsistencia de grupos cazadoresrecolectores. Magallania, 43(1), 231-249.

Sugrañes, N. (2011). Tecnología cerámica y estrategias de movilidad entre cazadores-recolectores de altura. El caso del sitio Valle Hermoso 1 (Malargüe, Mendoza). Intersecciones en Antropología, 12, 155-166.

Torres Robles, S. S. (2009). Variación geográfica de la composición y riqueza de plantas vasculares en los talares bonaerenses y su relación con el clima, sustrato, estructura del paisaje y uso. Tesis inédita de doctorado. Facultad de Ciencias Naturales y
Museo, Universidad Nacional de La Plata.

Vignati, M. (1931). Investigaciones antropológicas en el litoral marítimo subatlántico bonaerense. Notas Preliminares del Museo de La Plata, 1, 19-31.

Wolverton, S., Nagaoka, L., Densmore, J., \& Fullerton B. (2008). White tailed deer Harvest pressure and within-bone nutrient exploitation during the mid to late Holocene in Southeast Texas. Before Farming, 2 article 3. Recuperado de https://www.academia. edu/244235/White-tailed_deer_harvest_pressure and_within-bone_nutrient_exploitation_during_the mid-_to_late_Holocene_in_southeast_Texas_USA 
